\title{
Mechanistic Analysis of the Role of Metal Oxophilicity in the Hydrodeoxygenation of Anisole
}

\author{
Qiaohua Tan, ${ }^{1}$ Gonghua Wang, ${ }^{1}$ Alex Long, ${ }^{1}$ Arne Dinse,${ }^{2}$ Corneliu Buda, ${ }^{2}$ \\ John Shabaker, ${ }^{2}$ and Daniel E. Resasco ${ }^{1 *}$ \\ (1) School of Chemical, Biological and Materials Engineering, \\ University of Oklahoma, Norman, OK 73019 \\ (2) BP Corporation, Naperville, IL 60563
}

*Corresponding author. Email address: resasco@ ou.edu

\begin{abstract}
A combined experimental and theoretical comparative study of the hydrodeoxygenation (HDO) of anisole was conducted over Pt, $\mathrm{Ru}$, and Fe metals. In the experimental part, an inert silica support was used to directly compare the catalytic activity and selectivity of the three metals at $375{ }^{\circ} \mathrm{C}$ under $\mathrm{H}_{2}$ flow at atmospheric pressure. In parallel, for density functional theory (DFT) calculations the close-packed $\mathrm{Pt}(111), \mathrm{Ru}(0001)$, and $\mathrm{Fe}(110)$ surfaces were employed to compare the possible mechanisms on these metals. It was observed that over $\mathrm{Pt} / \mathrm{SiO}_{2}$ and $\mathrm{Ru} / \mathrm{SiO}_{2}$ catalysts, both phenol and benzene were the major products in a phenol/benzene ratio that decreased with the level of conversion. By contrast, over the $\mathrm{Fe} / \mathrm{SiO}_{2}$ catalyst, no phenol formation was detected, even at low conversions. The DFT results show that over all the three metal surfaces the dehydrogenation at the $-\mathrm{CH}_{3}$ side group occurs before the $\mathrm{C}-\mathrm{O}$ bond breaking. This removal of $\mathrm{H}$ atoms from the $-\mathrm{CH}_{3}$ group facilitates the activation of the aliphatic $\mathrm{C}_{\text {alkyl }} \mathrm{O}$ bond. Therefore, it can be concluded that a common intermediate for the three metals is a surface phenoxy and the significant differences between the three metals is related to the reactivity of this surface phenoxy. That is, over $\operatorname{Pt}(111)$ and $\operatorname{Ru}(0001)$ the phenoxy intermediate is hydrogenated to phenol, which in turn, can undergo further HDO to form benzene. This result is in agreement with the experiments over $\mathrm{Pt} / \mathrm{SiO}_{2}$ and $\mathrm{Ru} / \mathrm{SiO}_{2}$ catalysts. Over these catalysts, both phenol and benzene are major products, with the selectivity to benzene increasing with conversion at the expense of phenol. In contrast, over the Fe(110) surface, the strong metal oxophilicity makes the direct cleavage of the $\mathrm{C}-\mathrm{O}$ bond in the surface phenoxy easier than
\end{abstract}


hydrogenation to phenol. Thus, it is predicted that phenol is not formed over iron, but only benzene should be observed as HDO product at all conversion levels, which is also in agreement with the experimental observations.

\section{Keywords}

hydrodeoxygenation, HDO, anisole, platinum, ruthenium, iron, oxophilicity, density functional theory, DFT, phenolics

\section{Introduction}

The development of catalysts for the catalytic hydrodeoxygenation (HDO) of lignin-derived phenolic compounds is a very important step in the upgrading of biomass-derived streams to fuels and chemicals. Lignin-derived phenolic compounds include guaiacol, cresol, vanillin, eugenol, syringol, and others, which contain both $-\mathrm{OH}$ and $-\mathrm{OCH}_{3}$ functional groups attached directly to the aromatic ring [1-9]. Thus the hydrodeoxygenation of these phenolic compounds require catalysts that can break the aromatic $\mathrm{C}-\mathrm{O}$ bond to remove the $-\mathrm{OH}$ or $-\mathrm{OCH}_{3}$ groups and form $\mathrm{C}-\mathrm{H}$ bonds instead. While different catalysts including metals [2-11], metal sulfides [12-14], metal phosphides [15-19] and metal carbides [20-22] have been investigated in the HDO process, the supported metal catalysts such as $\mathrm{Pt}, \mathrm{Pd}, \mathrm{Ru}$ and $\mathrm{Fe}$ have been shown to be promising for the hydrodeoxygenation reactions of phenolic compounds [2-10]. Various aspects of the metal catalysts such as the incorporation of bifunctionality [23-31], use of bimetallics, [32-38] and metal-support effects [39-42] have been extensively studied. However, to determine how the chemical role of the different metals leads to different reaction pathways further investigation is needed.

Indeed, it is clear that different metals show different activity and selectivity for HDO reactions. Our previous experiments of $\mathrm{HDO}$ of m-cresol over $\mathrm{SiO}_{2}$-supported $\mathrm{Pt}, \mathrm{Ru}, \mathrm{Ni}, \mathrm{Fe}$ and $\mathrm{Ni}-\mathrm{Fe}$ catalysts at $300^{\circ} \mathrm{C}$ showed that the hydrogenation products 3-methylcyclohexanone and 3methylcyclohexanol are the major products over Pt and Ni catalysts, while the selectivity to the $\mathrm{HDO}$ product (toluene) is significantly enhanced over oxophilic metals, such as $\mathrm{Ru}, \mathrm{Fe}$, and $\mathrm{Ni}$ $\mathrm{Fe}[5,6,9]$. In a recent study, to understand how different metal catalysts lead to different product distributions in the HDO of m-cresol, we carried out DFT calculations and explored the reaction paths of m-cresol conversion on $\mathrm{Pt}(111)$ and $\mathrm{Ru}(0001)$ surfaces [9]. We found that direct 
deoxygenation (DDO) is unfavorable over $\mathrm{Pt}(111)$. On this metal, the reaction is thought to proceed through a keto tautomer intermediate, which undergoes hydrogenation of the carbonyl group followed by dehydration to form toluene and water. This HDO path occurs in parallel to the hydrogenation of the ring, which leads to 3-methylcyclohexanone and 3-methylcyclohexanol as major products. By contrast, over the more oxophilic Ru(0001) surface, the DDO pathway becomes more favorable than the tautomerization route. Moreover, our DFT calculations demonstrated a general correlation between the energy barrier for direct deoxygenation and the oxophilicity of metal surfaces, as assessed by the binding energy of $O$ to the metal surface. Similar trends have been reported by Hensley et al. [43] by comparing the paths of HDO of phenol over $\mathrm{Pd}(111)$ and $\mathrm{Fe}(110)$ surfaces. They found that the direct $\mathrm{C}-\mathrm{O}$ cleavage is not favorable over $\operatorname{Pd}(111)$ surface but favorable over the more oxophilic $\mathrm{Fe}(110)$ surface.

As opposed to the HDO of m-cresol and phenol, which requires the removal of -OH group, the HDO of anisole or guaiacol requires the removal of an $-\mathrm{OCH}_{3}$ group, which might proceed through different mechanisms since their molecular structures comprise two kinds of C-O bonds: the aromatic $\mathrm{C}_{\text {aryl }}-\mathrm{O}$ bond and the aliphatic $\mathrm{C}_{\mathrm{alkyl}} \mathrm{O}$ bond. The $\mathrm{HDO}$ of guaiacol has been investigated over different metal catalysts, such as Pd,[44, 45] Pt,[46-50] Ru,[51-53] and Fe [44, 54-56]. The product distribution seems to vary with the specific catalyst. For example, working with MgO-supported Pt catalysts, Gates et al. [48] found that catechol, phenol, and cyclohexanone are dominant products at low conversion (6\%), with selectivities of $25 \%, 51 \%$, and $17 \%$, respectively. This result would indicate that if both are primary products, phenol and catechol could be produced via demethoxylation and demethylation, respectively. Also, on a $\mathrm{Pt} / \mathrm{C}$ catalyst, Gao et al. [49] found that guaiacol yielded $40 \%$ phenol and $10 \%$ catechol. In this case, it was suggested that phenol production could follow two alternative pathways, direct demethoxylation and sequential demethylation/dehydration via catechol. Similarly, Boonyasuwat et al. [51] investigated the HDO of guaiacol over Ru catalysts on different supports, including C, $\mathrm{SiO}_{2}, \mathrm{Al}_{2} \mathrm{O}_{3}$, and $\mathrm{TiO}_{2}$. They found that, similar to the Pt catalyst, $\mathrm{Ru} / \mathrm{C}, \mathrm{Ru} / \mathrm{SiO}_{2}$ and $\mathrm{Ru} / \mathrm{Al}_{2} \mathrm{O}_{3}$ produced catechol and phenol as major products. However, on $\mathrm{Ru} / \mathrm{TiO}_{2}$ catalyst, the deoxygenation activity was significantly enhanced and catechol quickly converted, leaving phenol as the only major product. This unique behavior of $\mathrm{Ru} / \mathrm{TiO}_{2}$ is ascribed to the creation of synergic sites between $\mathrm{Ru}$ and $\mathrm{TiO}_{2}$ at the metal/support interface $[57,58]$.

In parallel, DFT calculations have been used to explore the mechanisms of guaiacol 
conversion on $\mathrm{Pt}(111)$ and $\mathrm{Ru}(0001)$ surfaces. For example, Chiu et al[52] and later Lu et al. [53] have independently explored the reaction pathways of guaiacol on $\mathrm{Ru}(0001)$. Both groups found that the most plausible path starts with the removal of $\mathrm{H}$ from the $-\mathrm{OH}$ group in the guaiacol molecule $\left(\mathrm{HO}-\mathrm{Ph}-\mathrm{OCH}_{3}\right)$ to form the $\mathrm{O}^{*}-\mathrm{Ph}-\mathrm{OCH}_{3}$ intermediate, which then goes through sequential dehydrogenation steps of the $-\mathrm{CH}_{3}$ group to form an $\mathrm{O}^{*}-\mathrm{Ph}-\mathrm{OCH}^{*}$ intermediate. Then, this $\mathrm{O}^{*}-\mathrm{Ph}-\mathrm{OCH}^{*}$ species is able to cleave the aliphatic $\mathrm{C}_{\text {alkyl }}-\mathrm{O}$ bond, forming a surface catecholate $\left(\mathrm{O}^{*}-\mathrm{Ph}-\mathrm{O} *\right)$. Subsequent hydrogenation of catecholate yields catechol, which in a second deoxygenation step can form phenol. These calculations agree well with the observed experimental results. Similar paths have been obtained by Lee et al. [50] for the conversion of guaiacol over the $\mathrm{Pt}(111)$ surface. They also have concluded that dehydrogenation of the $-\mathrm{OH}$ and $-\mathrm{CH}_{3}$ groups occurs before the cleavage of the $\mathrm{C}-\mathrm{O}$ bond.

The HDO of guaiacol over Fe catalysts has been studied by Olcese et al. [54] They found that, similar to the case of $\mathrm{Pt}$ and $\mathrm{Ru}$ catalysts, $\mathrm{Fe} / \mathrm{SiO}_{2}$ produces phenol as the main product. However, in contrast to $\mathrm{Pt}$ and $\mathrm{Ru}$, on which catechol is observed as an intermediate product, on Fe catechol is barely detected. Interestingly, it was observed that selectivity to catechol increased when co-feeding $\mathrm{H}_{2} \mathrm{O}$. That is, the near absence of catechol in the products over Fe may be ascribed to the fast conversion of catechol on clean Fe, or alternatively, it can be due to the high oxophilic of $\mathrm{Fe}$, which may facilitate the direct cleavage of the aromatic $\mathrm{C}-\mathrm{O}$ bond, preventing the evolution of catechol to the gas phase. In that case, the inhibition of this direct cleavage pathway by water would explain the observed increase in catechol selectivity.

Anisole is an attractive model compound since it only has the $-\mathrm{OCH}_{3}$ group pendant on the aromatic ring. Our group has previously studied the $\mathrm{HDO}$ of anisole over $\mathrm{Pt} / \mathrm{SiO}_{2}$ as well as bifunctional $\mathrm{Pt} / \mathrm{H}$-Beta catalysts [59]. We found that over a $\mathrm{Pt} / \mathrm{SiO}_{2}$ catalyst, phenol and $\mathrm{CH}_{4}$ are the major products at low space time $(\mathrm{W} / \mathrm{F})$, but at higher $\mathrm{W} / \mathrm{F}$ the yield of benzene increased at the expenses of phenol. Thus, we suggested that over Pt demethylation to phenol is the primary reaction, while benzene is produced by secondary HDO of phenol, rather than directly from anisole. Similar results were observed by Pichaikaran et al. [10] in the study of HDO of anisole over aluminosilicate-supported $\mathrm{Ru}$ and $\mathrm{Ni}$ catalysts. They found that phenol was the major product at low conversions.

In summary, while a number of experimental efforts have been reported about HDO of methoxy-aromatics, such as anisole and guaiacol, over different metals, the mechanism for the 
removal of the aromatic $-\mathrm{OCH}_{3}$ groups is not clear, as both possible paths, demethoxylation and demethylation, have been proposed. Also, the influence of the chemical nature of the metal catalyst, such as its oxophilicity, on the reaction pathways and hence the product distribution is not completely established yet. Therefore, in this work, we have carried out experiments probing $\mathrm{HDO}$ of anisole over $\mathrm{Pt}, \mathrm{Ru}$ and $\mathrm{Fe}$ catalysts, each one displaying a different degree of oxophilicity. The experiments have been combined with the DFT calculations to elucidate the mechanisms of the HDO of anisole over the three metal surfaces with the goal of determining the role of metal oxophilicity on reaction mechanisms.

\section{Experimental}

\subsection{Catalyst Preparation and Characterization}

Three silica-supported catalysts, $\mathrm{Pt} / \mathrm{SiO}_{2}$ (1 wt.\%), $\mathrm{Ru} / \mathrm{SiO}_{2}\left(9.4\right.$ wt.\%) and $\mathrm{Fe} / \mathrm{SiO}_{2}$ (5 wt.\%) catalysts were prepared by incipient wetness impregnation of the $\mathrm{SiO}_{2}$ support (HiSil 210, PPG, $\mathrm{S}_{\mathrm{BET}}=135 \mathrm{~m}^{2} / \mathrm{g}$ ) with an aqueous solution of $\mathrm{Pt}(\mathrm{IV})$ chloride hydrate, $\mathrm{Ru}(\mathrm{III})$ chloride hydrate and with an aqueous solution of Fe(III) nitrate hydrate, respectively, as described in previous work $[5,6,9,60]$. The $\mathrm{Pt} / \mathrm{Fe}_{2} \mathrm{O}_{3}$ (1 wt.\%) catalyst was prepared by incipient wetness impregnation of $\mathrm{Fe}_{2} \mathrm{O}_{3}\left(\mathrm{~S}_{\mathrm{BET}}=29.5 \mathrm{~m}^{2} / \mathrm{g}\right)$ with the aqueous solution of $\mathrm{Pt}(\mathrm{IV})$ chloride hydrate. After impregnation, the catalysts were dried at $120^{\circ} \mathrm{C}$ for $12 \mathrm{~h}$ and calcined at $500{ }^{\circ} \mathrm{C}$ for $4 \mathrm{~h}$. Before carrying out the reactions, the samples were pelletized, crushed, and sieved to 250-420 $\mu \mathrm{m}$ size range (Mesh No. 40-60). Transmission Electron Microscopy (TEM) images of catalyst samples were obtained in a JEOL 2000FX system. The samples were prepared by dispersing the catalyst powder in isopropanol, sonicating for 30 seconds and placing one drop of solution on holey-carbon coated $\mathrm{Cu}$ grids followed by drying. TEM images of the $\mathrm{Pt} / \mathrm{SiO}_{2}, \mathrm{Ru} / \mathrm{SiO}_{2}$ and $\mathrm{Fe} / \mathrm{SiO}_{2}$ samples have been shown in previous work, indicating average metal particle sizes of about 3.5, 5.2, and $23.4 \mathrm{~nm}$, respectively, as summarized in Table $1[5,6,9,60]$. These particle sizes suggest the flat planes dominate in all the three metal particles and the particle size effects are thus minimized, and the surface models can thus be used in the following DFT calculations.[61] A TEM image of the $\mathrm{Pt} / \mathrm{Fe}_{2} \mathrm{O}_{3}$ catalyst is shown and discussed below. Thermogravimetric analysis (TGA) of the $\mathrm{Pt} / \mathrm{Fe}_{2} \mathrm{O}_{3}$ catalyst sample was carried out in a $\mathrm{H}_{2}$ : $\mathrm{Ar}$ (80:20) gas mixture with a total flow rate of $100 \mathrm{~cm}^{3} / \mathrm{min}$ and a linear temperature increase of 10 ${ }^{\circ} \mathrm{C} / \mathrm{min}$. 


\subsection{Reaction Conditions}

The HDO activity and product distribution from conversion of anisole over the three catalysts were measured in a fixed-bed quartz-tube reactor ( $6 \mathrm{~mm}$ outer diameter) under $\mathrm{H}_{2}$ flow at atmospheric pressure. The flow reaction system is equipped with a mass flow controller and a syringe pump for the continuous injection of anisole. Pelletized catalysts were packed in the reactor between two layers of glass beads and quartz wool to improve flow and temperature uniformity. The catalysts were pre-reduced in flowing $\mathrm{H}_{2}(60 \mathrm{ml} / \mathrm{min})$ for $1 \mathrm{~h}$ at $400{ }^{\circ} \mathrm{C}$ for $\mathrm{Pt} / \mathrm{SiO}_{2}$ and $\mathrm{Ru} / \mathrm{SiO}_{2}$ while at $450{ }^{\circ} \mathrm{C}$ for $\mathrm{Fe} / \mathrm{SiO}_{2}$ and $\mathrm{Pt} / \mathrm{Fe}_{2} \mathrm{O}_{3}$. After reduction, the reaction was conducted at $375{ }^{\circ} \mathrm{C}$ under the same $\mathrm{H}_{2}$ flow rate. A $0.3 \mathrm{ml} / \mathrm{h}$ flow of liquid anisole was fed continuously from the syringe pump and vaporized into the $\mathrm{H}_{2}$ stream. Space time (W/F), defined as the ratio of catalyst mass $(\mathrm{W})$ to mass flow rate $(\mathrm{F})$, was adjusted for different runs to investigate the reaction kinetics. In each run at a different $\mathrm{W} / \mathrm{F}$, the products were collected and analyzed after 15 min on stream, which is long enough to allow steady state to be established, and also short enough to minimize the effect of catalyst deactivation. The reaction products were analyzed and quantified by online gas chromatography, using an HP-5 column (30 m, $0.25 \mu \mathrm{m})$ and a flame ionization detector (FID). All lines were kept heated at $250{ }^{\circ} \mathrm{C}$ to avoid product condensation. The carbon selectivity for each product was calculated according to the expression:

Selectivity $(\%)=$ moles of $C$ in the target product $/$ moles of $C$ in all the products

where the moles of $\mathrm{C}$ in each product are calculated as the number of $\mathrm{C}$ atoms in the particular product molecule multiplied by the moles of this product. Methane formed from the side group of anisole was not counted in the analysis of selectivity. When the total moles of methane in the product exceed the sum of phenol and benzene moles, it can be concluded that this additional methane arises from cracking of some of the aromatic rings. Therefore the "methane from cracking" value was obtained by subtracting the moles of phenol + benzene in the products from the total moles of methane.

\subsection{Density Functional Theory Calculations}

The calculations were carried out using periodic plane-wave gradient-corrected density functional theory methods implemented in the Vienna ab initio Simulation Package (VASP)[6265]. The PBE functional was used to calculate the exchange correlation energy within the 
generalized gradient approximation (GGA) [66]. The DFT-D3 method was used to account for van der Waals (vdW) interactions [67]. The projector augmented wave method (PAW) which uses the exact shape of the valence wave functions instead of pseudo-wave functions, was employed to describe the electron-ion interactions [68]. The cutoff energy of $400 \mathrm{eV}$ was applied for the plane-wave basis set to represent valence electrons.

The close-packed 4x4 $\mathrm{Pt}(111), \mathrm{Ru}(0001)$ and $\mathrm{Fe}(110)$ surfaces with four metal layers and 15 $\AA$ of vacuum separating the slabs in the z-direction were used to model the $\mathrm{Pt}$ and $\mathrm{Ru}$ and $\mathrm{Fe}$ catalysts. The top two metal layers were allowed to relax during the calculations, whereas the bottom two layers were held fixed to their initial bulk position. The electronic energies were converged within $10^{-6} \mathrm{eV}$ limit. The geometric structures for all of reactants, intermediates and products were optimized until the forces on each atom were below $0.01 \mathrm{eV} / \AA$. A $3 \times 3 \times 1$ k-point mesh was used to sample the first Brillouin zone [69]. The energies of the adsorbates in vacuum were calculated spin-polarized using an $18 \times 18 \times 18 \AA$ unit cell with the $\Gamma$ only k-point mesh.

Transition state searches were performed using the dimer method[70] with the initial guesses for the transition state structure and the reaction trajectory obtained through the nudged elastic band (NEB) method [71].

The Gibbs free energies for the adsorption of closed-shell species at $375{ }^{\circ} \mathrm{C}$ and $1 \mathrm{~atm}$ were estimated by including the entropy, which in turn was calculated according to standard thermodynamic procedures [72]. That is, the vibrational entropy was calculated from vibrational frequencies derived from DFT frequency calculations; the translational and rotational entropies of adsorbed species were assumed to be zero. For gas-phase species, the translational and rotational entropies were calculated from statistical thermodynamics [72].

\section{Results and Discussion}

\subsection{Product distribution from anisole conversion over $\mathrm{Pt} / \mathrm{SiO}_{2}, \mathrm{Ru} / \mathrm{SiO}_{2}$ and $\mathrm{Fe} / \mathrm{SiO}_{2}$}

The product selectivity observed during the conversion of anisole over the $\mathrm{Pt} / \mathrm{SiO}_{2}, \mathrm{Ru} / \mathrm{SiO}_{2}$ and $\mathrm{Fe} / \mathrm{SiO}_{2}$ catalysts at $375{ }^{\circ} \mathrm{C}$ is summarized in Table 2. Over $\mathrm{Pt} / \mathrm{SiO}_{2}$ at a low conversion of $15 \%$, phenol was the dominant product with $93 \%$ selectivity. Benzene was also produced, but at a much lower selectivity (7\%). No ring hydrogenation products (e.g. methoxycyclohexanone or methoxycyclohexanol) were observed, since at $375{ }^{\circ} \mathrm{C}$ hydrogenation is thermodynamically unfavorable. 
Methane, generated from the methoxy side group and/or the hydrogenolysis (ie. cracking) of the aromatic ring, was observed in the products. In contrast, no methanol was observed, which suggests that demethylation rather than demethoxylation is the preferred reaction path of the methoxy group in anisole. In fact, the $\mathrm{CH}_{4} /$ (phenol+benzene) molar ratio was calculated to be about 1.0. Since no toluene or other methylated products are observed, this value indicates that, on $\mathrm{Pt}, \mathrm{CH}_{4}$ comes exclusively from the anisole methoxy group rather than cracking of the aromatic ring. A comparable product distribution has been previously reported for the HDO of anisole on Pt [59].

The evolution of products as a function of space-time (W/F) was also investigated on the $\mathrm{Pt} / \mathrm{SiO}_{2}$ catalyst. As shown in Figure 1A, at low conversion, the primary product is clearly phenol, the only product with a non-zero initial derivative with respect to W/F. As conversion increases with W/F, the yield of benzene keeps increasing until finally reaches $100 \%$ at the expense of phenol that reaches a maximum at about $\mathrm{W} / \mathrm{F}=0.05$, and finally decreases progressively to zero. Clearly, this trend demonstrates a series $\mathrm{A} \rightarrow \mathrm{B} \rightarrow \mathrm{C}$ reaction such that over the $\mathrm{Pt} / \mathrm{SiO}_{2}$ catalyst anisole first undergoes demethylation to form $\mathrm{CH}_{4}$ and phenol, which then undergoes the HDO reaction to form benzene and water. It is also clear that the direct demethoxylation of anisole to benzene does not occur over Pt.

Over $\mathrm{Ru} / \mathrm{SiO}_{2}$ catalyst at low conversion (5\%), both phenol and benzene products were observed, as found using $\mathrm{Pt} / \mathrm{SiO}_{2}$. However, even at this low conversion the phenol/benzene ratio on $\mathrm{Ru}$ was much lower than that observed on Pt. Similarly, methane rather than methanol was observed in the products on $\mathrm{Ru} / \mathrm{SiO}_{2}$ suggesting demethylation rather than demethoxylation occurs in the HDO of anisole. However, the $\mathrm{CH}_{4} /$ aromatics ratio, which is about 22 , is much higher than the stoichiometric ratio of 1.0 observed on Pt, indicating that significant cracking of the aromatic rings occurs over $\mathrm{Ru} / \mathrm{SiO}_{2}$. In fact, as shown in Table 2, the selectivity towards methane from cracking (75\%) is even higher than the selectivity of phenol and benzene combined (9\% and 16\%) at 5\% conversion. The significant extent of cracking of the aromatic ring is consistent with that previously observed during the $\mathrm{HDO}$ of m-cresol over $\mathrm{Ru} / \mathrm{SiO}_{2}$ [9]. As discussed previously in the $\mathrm{HDO}$ of $\mathrm{m}$-cresol over $\mathrm{Ru} / \mathrm{SiO}_{2}$, the cracking of the aromatic ring may also lead to lower turnover frequencies over the Ru catalyst (Table 2), as the carbon species generated from cracking can block the metal surface [9]. Figure 1B shows the evolution of products as a function of space-time (W/F) over $\mathrm{Ru} / \mathrm{SiO}_{2}$. It is observed that as anisole 
conversion increases the yields of both benzene and phenol increase, but the yield of the latter remains low over the entire range of $\mathrm{W} / \mathrm{F}$ investigated.

Finally, over the $\mathrm{Fe} / \mathrm{SiO}_{2}$ catalyst the differences versus $\mathrm{Pt}$ are even more striking. As shown in Table 2, benzene is the dominant product with a selectivity of $85 \%$ at a low anisole conversion (8\%). Interestingly, toluene is also formed with the selectivity of $9 \%$. As previously discussed, this product is obtained via transalkylation catalyzed by acid sites resulting from unreduced iron oxide, followed by hydrodeoxygenation on the metal particles. Still no methanol, but rather methane, was observed in the products. The $\mathrm{CH}_{4}$ /aromatics ratio is calculated to be 1.4, indicating about 6\% anisole underwent cracking reactions. Remarkably, even at the low conversion of this run, no phenol was observed in the products, which is dramatically different from the cases of $\mathrm{Ru}$ and particularly $\mathrm{Pt}$. This result is consistent with the observation that no catechol was observed from guaiacol conversion over $\mathrm{Fe} / \mathrm{SiO}_{2}$ [54].

The corresponding evolution of products from anisole conversion on $\mathrm{Fe} / \mathrm{SiO}_{2}$ as a function of $\mathrm{W} / \mathrm{F}$ is shown in Figure 1C. It is remarkable that no phenol was observed in the products in the broad anisole conversion range investigated (8-50\%).

Another way to illustrate the differences displayed by a highly oxophilic metal (Fe) and a less-oxophilic metal (Pt) in the HDO of anisole is to follow the change in selectivity as a function of catalyst deactivation over the two metals. Figure 2 summarizes the variation of the relative molar fractions of phenol $(\mathrm{P})$ and benzene $(\mathrm{B})$, calculated as $\mathrm{P} /(\mathrm{P}+\mathrm{B})$ and $\mathrm{B} /(\mathrm{P}+\mathrm{B})$, respectively, as a function of time-on-stream over the Pt and Fe catalysts. It is clear that on $\mathrm{Pt} / \mathrm{SiO}_{2}$, as the catalyst deactivates with time-on-stream and the conversion decreases, the molar fraction of benzene decreases and the molar fraction of phenol in turn increases. By contrast, on $\mathrm{Fe} / \mathrm{SiO}_{2}$ the relative molar fraction of benzene remains at $100 \%$ and no phenol is observed at any time-on-stream.

Clearly, the absence of phenol suggests that a different mechanism is operative over $\mathrm{Fe} / \mathrm{SiO}_{2}$ from that over $\mathrm{Pt} / \mathrm{SiO}_{2}$ and $\mathrm{Ru} / \mathrm{SiO}_{2}$. As shown in previous temperature programmed reduction (TPR) studies, oxidized $\mathrm{Fe} / \mathrm{SiO}_{2}$ is more difficult to reduce than $\mathrm{Pt}$ or $\mathrm{Ru}$ catalysts. In fact, it may require temperatures as high as $650{ }^{\circ} \mathrm{C}$ to complete the hydrogen uptake. However, XRD shows that partial reduction occurs at $450{ }^{\circ} \mathrm{C}$, and a significant fraction of metallic $\mathrm{Fe}$ is formed at these temperatures [60]. The addition of small amounts of Pt, greatly facilitates the reduction of Fe oxide. Therefore, to examine the active sites on metallic Fe, a Pt-doped $\mathrm{Fe}_{2} \mathrm{O}_{3}$ catalyst was 
compared to undoped Fe oxide. The TGA of $\mathrm{Fe}_{2} \mathrm{O}_{3}$ and $\mathrm{Pt} / \mathrm{Fe}_{2} \mathrm{O}_{3}$ are shown in Figure 3. It is clear that the reduction of the undoped $\mathrm{Fe}_{2} \mathrm{O}_{3}$ proceeds in two steps (from $\mathrm{Fe}_{2} \mathrm{O}_{3}$ to $\mathrm{Fe}_{3} \mathrm{O}_{4}$ which later converts to metallic Fe). The first step finishes at about $300{ }^{\circ} \mathrm{C}$, while the second finishes at about $550^{\circ} \mathrm{C}$, in agreement with previous studies [73]. It is clear that doping with small amounts of Pt (1\%) facilitates the reduction of $\mathrm{Fe}_{2} \mathrm{O}_{3}$, shifting the two steps to lower temperatures, as seen before in $\mathrm{Ni}-\mathrm{Fe}$ and $\mathrm{Pd}-\mathrm{Fe}$ catalysts $[60,74]$. At about $450{ }^{\circ} \mathrm{C}$, the Pt-doped $\mathrm{Fe}_{2} \mathrm{O}_{3}$ is totally reduced to metallic Fe. This is further confirmed by the TEM images and the selected area electron diffraction (SAED) patterns of $\mathrm{Pt} / \mathrm{Fe}_{2} \mathrm{O}_{3}$ after reduction, as shown in Figure 4. The TEM images show that $\mathrm{Fe}_{2} \mathrm{O}_{3}$, originally displaying a geometric and crystalline shape, adopts a "glassy-like" morphology upon reduction, corresponding to metallic Fe coated with a thin layer of oxide, which is formed upon exposure to air. The SAED patterns of $\mathrm{Fe}_{2} \mathrm{O}_{3}$ before and after the reduction were compared with the standard diffraction data of metallic $\mathrm{Fe}$ and $\mathrm{Fe}$ oxides structures, as shown in the Figure S1. The comparison clearly shows that the $\gamma-\mathrm{Fe}_{2} \mathrm{O}_{3}$ phase is present in the unreduced sample; but, after reduction, it becomes metallic $\alpha$-Fe.

The HDO of anisole was then conducted over the $\mathrm{Pt} / \mathrm{Fe}_{2} \mathrm{O}_{3}$ catalyst. The product distribution, summarized in Table 2, shows that at low conversion (7\%), the dominant product is benzene (selectivity 80\%) while no phenol is formed. This behavior is typical of the $\mathrm{Fe} / \mathrm{SiO}_{2}$ catalyst rather than $\mathrm{Pt}$. In fact, the only primary product on $\mathrm{Pt} / \mathrm{SiO}_{2}$ is phenol. That is, the dominant active function in $\mathrm{Pt} / \mathrm{Fe}_{2} \mathrm{O}_{3}$ is iron. More importantly, although $\mathrm{Fe} / \mathrm{SiO}_{2}$ contains both oxide and metallic Fe, the dominant HDO activity is due to metallic Fe. Therefore, the observed differences in product distributions over $\mathrm{Pt}, \mathrm{Ru}$ and $\mathrm{Fe}$ catalysts are due to the different nature of the three metals, rather than differences in oxidation state. In the following sections, we describe the DFT calculations that we have carried out to explore the reaction pathways of the HDO of anisole over $\mathrm{Pt}, \mathrm{Ru}$ and $\mathrm{Fe}$ metal surfaces and explain the different product distributions experimentally observed over the $\mathrm{Pt} / \mathrm{SiO}_{2}, \mathrm{Ru} / \mathrm{SiO}_{2}$, and $\mathrm{Fe} / \mathrm{SiO}_{2}$ catalysts.

\subsection{Adsorption of Anisole on Pt(111), Ru(0001) and Fe(110) surfaces}

The energies of different adsorption configurations of the anisole molecule over $\mathrm{Pt}(111)$, $\mathrm{Ru}(0001)$ and $\mathrm{Fe}(110)$ surfaces were calculated and compared as shown in Figure S2. From this analysis it can be concluded that the most favorable adsorption mode on these three surfaces is the 'bridge 30' configuration, as shown in Figure 5. In this adsorption mode, anisole binds flat to 
four metal $(\mathrm{Pt}, \mathrm{Ru}$, or $\mathrm{Fe})$ atoms via the six aromatic $\mathrm{C}$ atoms. This mode is similar to those reported for other adsorbed phenolic compounds such as phenol, cresol, and guaiacol on $\operatorname{Pt}(111)$, $\mathrm{Ru}(0001), \mathrm{Fe}(110)$, and other surfaces $[9,43,50,52,53,75]$. The corresponding adsorption energy for anisole on $\mathrm{Pt}(111)$ surface is calculated to be $-225 \mathrm{~kJ} / \mathrm{mol}$ (Table 3), which is close to the reported adsorption energy of guaiacol on $\mathrm{Pt}(111)(-233 \mathrm{~kJ} / \mathrm{mol})$ [50]. The adsorption energy of anisole on $\mathrm{Ru}(0001)$ is calculated to be $-263 \mathrm{~kJ} / \mathrm{mol}$, slightly higher than the reported adsorption energy of guaiacol on $\mathrm{Ru}(0001)(-237 \mathrm{~kJ} / \mathrm{mol})$ [52]. This calculated adsorption energy of anisole on $\mathrm{Ru}(0001)$ is also higher than the adsorption energy of anisole on $\mathrm{Pt}(111)$, indicating a stronger binding of anisole to $\mathrm{Ru}(0001)$ than $\mathrm{Pt}(111)$. This trend is consistent with the differences in m-cresol adsorption energy between $\operatorname{Pt}(111)$ and $\operatorname{Ru}(0001)$ surfaces [9]. Finally, the adsorption energy of anisole on $\mathrm{Fe}(110)$ surface is calculated to be $-232 \mathrm{~kJ} / \mathrm{mol}$, slightly higher than that on $\operatorname{Pt}(111)$ but lower than that on $\operatorname{Ru}(0001)$.

The adsorption energy of atomic oxygen on $\mathrm{Pt}(111), \mathrm{Ru}(0001)$ and $\mathrm{Fe}(110)$ surfaces were also calculated the and used as a measurement of the oxophilicity of these three metals. The adsorption energies for $\mathrm{O}$ on $\mathrm{Pt}(111), \mathrm{Ru}(0001)$, and $\mathrm{Fe}(110)$ were calculated to be $-481 \mathrm{~kJ} / \mathrm{mol}$, $650 \mathrm{~kJ} / \mathrm{mol}$ and $-698 \mathrm{~kJ} / \mathrm{mol}$ respectively (Table 3), indicating that the order of metal oxophilicity is $\mathrm{Pt}(111)<<\mathrm{Ru}(0001)<\mathrm{Fe}(110)$.

\subsection{Reaction paths for HDO of anisole over Pt(111)}

\subsection{1 $\mathrm{C}_{\text {aryl }} \mathrm{O}$ activation of anisole}

One might predict that after adsorption on $\operatorname{Pt}(111)$ surface, the adsorbed anisole could undergo $\mathrm{C}_{\mathrm{aryl}} \mathrm{O}$ breaking (demethoxylation) to remove the $-\mathrm{OCH}_{3}$ and form a phenyl intermediate, which could be successively hydrogenated to benzene. However, this is neither supported by experiments, nor as shown below, by DFT calculations. As shown in Figure 6A, the calculation for this unfavorable path predict that the $\mathrm{C}_{\text {aryl-}} \mathrm{O}$ bond would gradually elongate from $1.35 \AA$ in the reactant to $2.53 \AA$ in the transition state. At the same time, the $\mathrm{OCH}_{3}$ group would approach the metal surface with the Pt-O distance decreasing from $3.31 \AA$ in the reactant to 2.06 $\AA$ in the transition state. This transition state structure is similar to the one we reported previously for the direct dehydroxylation of m-cresol over $\operatorname{Pt}(111)$ [9] and, as in that case, the resulting activation energy is predicted to be exceedingly high $(258 \mathrm{~kJ} / \mathrm{mol})$. The corresponding activation energy for the dehydroxylation of m-cresol that we reported previously was similarly 
high (242 kJ/mol)[9] and of the same order as that calculated for guaiacol on Pt(111), $243 \mathrm{~kJ} / \mathrm{mol}$ [50]. Likewise, the reaction energy for the demethoxylation reaction of anisole over $\operatorname{Pt}(111)$ is calculated to be highly endothermic $(147 \mathrm{~kJ} / \mathrm{mol})$ and similar to the one reported for the demethoxylation of guaiacol $(140 \mathrm{~kJ} / \mathrm{mol})$ [50]. That is, the exceedingly high barrier and the highly endothermic nature confirm that the direct demethoxylation of anisole is unfavorable over $\mathrm{Pt}$, as deduced from the experimentally observed evolution of products with conversion (Fig. 1.A).

\subsection{2 $C_{\text {alkyl-O }} \mathrm{O}$ activation of anisole}

We should also consider the possibility that the adsorbed anisole on $\operatorname{Pt}(111)$ could undergo demethylation to remove the $-\mathrm{CH}_{3}$ group to form the phenoxy intermediate, which can then form phenol via hydrogenation. Figure 6A shows the reactant, transition state, and product structures for this demethylation reaction. Here, in the transition state, the $\mathrm{C}_{\text {alkyl }} \mathrm{O}$ bond stretches to $2.11 \AA$ from the original $1.44 \AA$ in the reactant. The corresponding activation energy for this step is predicted to be $200 \mathrm{~kJ} / \mathrm{mol}$, slightly higher than the one reported for the demethylation of guaiacol over Pt(111) (181 kJ/mol) [50]. While this energy barrier is about $60 \mathrm{~kJ} / \mathrm{mol}$ lower than the one for demethoxylation described above, it is still significantly high. Therefore, other optional reaction paths were analyzed, as shown below.

\subsubsection{C-H activation of anisole}

It has been reported that initial dehydrogenation steps can facilitate the cleavage of $\mathrm{C}-\mathrm{O}$ and C-C bonds in hydrogenolysis of alcohols, polyols, cyclic ethers and alkanes [76-78]. Thus, we have investigated the possibility that dehydrogenation of anisole at the $-\mathrm{CH}_{3}$ group might be the initiation step. As shown in Figure $6 \mathrm{~A}$, one $\mathrm{H}$ atom can be removed from the $-\mathrm{CH}_{3}$ group to form adsorbed $-\mathrm{CH}_{2} *$ and $\mathrm{H}^{*}$ species with a relatively low energy barrier $(125 \mathrm{~kJ} / \mathrm{mol})$ in comparison to the demethoxylation $(258 \mathrm{~kJ} / \mathrm{mol})$ and demethylation $(200 \mathrm{~kJ} / \mathrm{mol})$ pathways described above. The reaction energy is only slightly endothermic $(12 \mathrm{~kJ} / \mathrm{mol})$, which indicates that this pathway is kinetically and thermodynamically more favorable than the others.

\subsubsection{Subsequent dehydrogenations and $\mathrm{C}$-O bond cleavage:}

After one $\mathrm{H}$ atom was removed from the $-\mathrm{CH}_{3}$ substituent, the $\mathrm{Ph}-\mathrm{O}-\mathrm{CH}_{2} *$ species formed 
could undergo cleavage of the $\mathrm{C}_{\text {aryl }}-\mathrm{O}$ or $\mathrm{C}_{\text {alkyl }}-\mathrm{O}$ bonds. However, as shown in Figure $6 \mathrm{~B}$, the successive dehydrogenation of the $\mathrm{Ph}-\mathrm{O}-\mathrm{CH}_{2} *$ intermediate to form the $\mathrm{Ph}-\mathrm{O}-\mathrm{CH}$ * has a lower energy barrier and more favorable reaction energy than the direct cleavage of any of the two C-O bonds. Thus, the activation energy for successive dehydrogenation is only $79 \mathrm{~kJ} / \mathrm{mol}$, compared to 227 and $90 \mathrm{~kJ} / \mathrm{mol}$ for the cleavages of the $\mathrm{C}_{\text {aryl }}-\mathrm{O}$ and $\mathrm{C}_{\text {alkyl }} \mathrm{O}$ bonds, respectively. This second dehydrogenation step is also about $34 \mathrm{~kJ} / \mathrm{mol}$ more exothermic than the first dehydrogenation step with an overall reaction energy of $-22 \mathrm{~kJ} / \mathrm{mol}$. This trend is consistent with the results found for the hydrogenolysis of methyltetrahydrofuran [78]. In that case, removal of a second $\mathrm{H}$ atom was found to be easier than removal of the first $\mathrm{H}$ atom at the same C. Also, compared to the $\mathrm{C}_{\text {alkyl }}-\mathrm{O}$ and $\mathrm{C}_{\text {aryl }}-\mathrm{O}$ bond breaking, the dehydrogenation paths of the $\mathrm{Ph}-\mathrm{O}-\mathrm{CH}_{2}{ }^{*}$ intermediate is less endothermic, indicating that the second step in the reaction should be a second dehydrogenation to form $\mathrm{Ph}-\mathrm{O}-\mathrm{CH}^{*}$. This trend is consistent with results of Lee et al. [50] who found that in the conversion of guaiacol the less saturated is the $\mathrm{C}$ of the side group, the easier is the demethylation. This trend also holds for the $\mathrm{C}_{\text {aryl- }} \mathrm{O}$ breaking reactions of $\mathrm{Ph}-\mathrm{O}-\mathrm{CH}_{\mathrm{x}}$ $(\mathrm{x}=1 \sim 3)$. Thus, the activation energy and reaction energy for the $\mathrm{C}_{\text {aryl }} \mathrm{O}$ breaking of $\mathrm{Ph}-\mathrm{O}-\mathrm{CH}^{*}$ $(150 / 70 \mathrm{~kJ} / \mathrm{mol})$ are lower than for the $\mathrm{C}_{\text {aryl- }} \mathrm{O}$ breaking of $\mathrm{Ph}-\mathrm{O}-\mathrm{CH}_{3}(258 / 147 \mathrm{~kJ} / \mathrm{mol})$ and $\mathrm{Ph}$ $\mathrm{O}-\mathrm{CH}_{2} *(227 / 126 \mathrm{~kJ} / \mathrm{mol})$.

As shown in Figure 6C, once the $\mathrm{Ph}-\mathrm{O}-\mathrm{CH}^{*}$ species has been formed, removal of the last $\mathrm{H}$ from the $\mathrm{C}$ becomes more difficult with a barrier of $124 \mathrm{~kJ} / \mathrm{mol}$ and an endothermic reaction energy $(32 \mathrm{~kJ} / \mathrm{mol})$. This finding is in agreement with DFT calculations of the sequential dehydrogenation of $\mathrm{CH}_{4}$ over $\mathrm{Pt}(111)$, in which the last dehydrogenation step has a higher barrier $(120 \mathrm{~kJ} / \mathrm{mol})$ than the first three dehydrogenation steps [79]. Nevertheless, the $\mathrm{C}_{\text {alkyl }}-\mathrm{O}$ bond can now be easily broken to remove the $\mathrm{CH}^{*}$ group and form the phenoxy intermediate, with an activation energy of only $83 \mathrm{~kJ} / \mathrm{mol}$ and an exothermic reaction energy of $-49 \mathrm{~kJ} / \mathrm{mol}$. Thus, this seems to be the most favorable path.

\subsubsection{Proposed reaction pathway for HDO of anisole over Pt(111)}

From the discussions above, the most plausible path over $\operatorname{Pt}(111)$ starts with anisole undergoing two sequential dehydrogenation steps from the $-\mathrm{CH}_{3}$ substituent to form a $\mathrm{Ph}-\mathrm{O}-\mathrm{CH}^{*}$ intermediate, which then breaks the $\mathrm{C}_{\text {alkyl }} \mathrm{O}$ bond and forms a phenoxy intermediate. Moreover, comparing the $\mathrm{C}_{\text {alkyl-}} \mathrm{O}$ breaking and $\mathrm{C}_{\text {aryl }}-\mathrm{O}$ breaking reactions of anisole $\left(\mathrm{Ph}-\mathrm{O}-\mathrm{CH}_{3}\right), \mathrm{Ph}-\mathrm{O}-$ 
$\mathrm{CH}_{2} *$ and $\mathrm{Ph}-\mathrm{O}-\mathrm{CH}^{*}$ respectively in Figure 6, we see that the energy barriers for the $\mathrm{C}_{\text {alkyl- }} \mathrm{O}$ cleavage are always lower than those for $\mathrm{C}_{\text {aryl-O }} \mathrm{O}$ cleavage, suggesting that over $\mathrm{Pt}(111)$, demethylation is always more favorable than demethoxylation.

The final step to consider is the fate of the phenoxy intermediate formed on the surface. As shown in Figure 7, this intermediate can either undergo hydrogenation to form phenol or C-O cleavage to form surface phenyl. The activation energy for hydrogenation is indeed very low on $\mathrm{Pt}(111), 17 \mathrm{~kJ} / \mathrm{mol}$, with an exothermic reaction energy of $-22 \mathrm{~kJ} / \mathrm{mol}$. The low barrier and exothermicity of this reaction suggest that phenol should be readily formed on Pt catalysts, as experimentally verified (see Table 2 above). In contrast, the deoxygenation of the phenoxy intermediate to form a phenyl intermediate that would lead to benzene as a primary product is extremely difficult on Pt, with an activation energy as high as $270 \mathrm{~kJ} / \mathrm{mol}$ and an endothermic reaction energy of $140 \mathrm{~kJ} / \mathrm{mol}$. Figure $8 \mathrm{~A}$ shows the energy diagrams for the hydrogenation and deoxygenation reactions of phenoxyl to form respectively phenol and benzene on $\operatorname{Pt}(111)$. It is clear that the hydrogenation path towards phenol is more favorable with a much lower overall energy barrier than deoxygenation. Therefore, we can conclude that the HDO of anisole over $\operatorname{Pt}(111)$ proceeds via demethylation to phenol rather than the demethoxylation to benzene, as experimentally verified (see Section 3.1). Once phenol is formed and desorbs to the gas phase, it can further undergo HDO to benzene by the tautomerization-hydrogenation-dehydration mechanism previously demonstrated in the HDO of m-cresol over Pt catalyst [9]. This anisole $\rightarrow$ phenol $\rightarrow$ benzene $(\mathrm{A} \rightarrow \mathrm{B} \rightarrow \mathrm{C}$ ) series reaction for HDO of anisole on $\mathrm{Pt}$ is in agreement with the typical behavior observed experimentally as a function of conversion (Fig. 1 A).

\subsection{Reaction Paths for HDO of Anisole over Ru(0001)}

$\mathrm{Ru}(0001)$ was the second surface investigated by DFT calculations as a catalyst for the HDO of anisole. As summarized in Figure 9, the transition state structure for the $\mathrm{C}_{\text {aryl }}-\mathrm{O}$ bond breaking (demethoxylation) of the adsorbed anisole on $\mathrm{Ru}(0001)$ is similar to that obtained over $\mathrm{Pt}(111)$, with the $\mathrm{C}_{\text {aryl- }} \mathrm{O}$ bond distance increasing from 1.39 to $2.01 \AA$ and the $-\mathrm{OCH}_{3}$ binding to one neighboring $\mathrm{Ru}$ atom with a $\mathrm{Ru}-\mathrm{O}$ distance of $2.15 \AA$. However, the activation energy for this step on $\mathrm{Ru}(0001), 99 \mathrm{~kJ} / \mathrm{mol}$, is much lower than that calculated for the same reaction on $\mathrm{Pt}(111)$, $258 \mathrm{~kJ} / \mathrm{mol}$, but very close to the barrier $(98 \mathrm{~kJ} / \mathrm{mol})$ that we previously calculated for the cleavage of $\mathrm{C}_{\text {aryl-}} \mathrm{O}$ bond of m-cresol over $\mathrm{Ru}(0001)$ [9]. Similarly, Chiu et al. [53] reported an 
activation energy of $102 \mathrm{~kJ} / \mathrm{mol}$ for the demethoxylation of guaiacol over the same surface. The difference between the barriers over $\mathrm{Ru}$ and $\mathrm{Pt}$ is consistent with the trend that we previously reported for the activation energies of the m-cresol dehydroxylation [9]. The direct demethoxylation via $\mathrm{C}_{\text {aryl }} \mathrm{O}$ bond cleavage is highly exothermic over $\mathrm{Ru}(0001),-63 \mathrm{~kJ} / \mathrm{mol}$, while being highly endothermic $(147 \mathrm{~kJ} / \mathrm{mol})$ over $\operatorname{Pt}(111)$.

The second reaction path investigated over $\mathrm{Ru}(0001)$ was the cleavage of the $\mathrm{C}_{\text {alkyl- }} \mathrm{O}$ bond that results in the formation of $\mathrm{CH}_{3}{ }^{*}$ and phenoxy surface intermediates, as shown in Figure 9. This path is more exothermic on $\mathrm{Ru}(0001)(-91 \mathrm{~kJ} / \mathrm{mol})$ and it involves a lower energy barrier $(135 \mathrm{~kJ} / \mathrm{mol})$ than on $\mathrm{Pt}(111)(200 \mathrm{~kJ} / \mathrm{mol})$, due to the stronger oxophilicity of $\mathrm{Ru}$. However, this activation energy is higher than that for the $\mathrm{C}_{\text {aryl- }} \mathrm{O}$ bond breaking. Moreover, as described below, the removal of a $\mathrm{H}$ atom at the $-\mathrm{CH}_{3}$ group to form $\mathrm{Ph}-\mathrm{O}-\mathrm{CH}_{2} *$ has an even lower activation energy $(73 \mathrm{~kJ} / \mathrm{mol})$. This difference suggests that dehydrogenation is the most favorable path for the adsorbed anisole over $\mathrm{Ru}(0001)$, similar to the case on the $\operatorname{Pt}(111)$ surface. Also, it can be expected that after the first dehydrogenation at the $-\mathrm{CH}_{3}$ side group, the $\mathrm{Ph}-\mathrm{O}-\mathrm{CH}_{2} *$ intermediate could undergo one of these three possibilities: cleavage of one of the two C-O bonds, or further dehydrogenation of the $-\mathrm{CH}_{2}$ group. As shown in Fig. 9, the dehydrogenation of $\mathrm{Ph}-\mathrm{O}-\mathrm{CH}_{2} *$ to $\mathrm{Ph}-\mathrm{O}-\mathrm{CH}^{*}$ on $\mathrm{Ru}$ exhibits the lowest activation energy (only $14 \mathrm{~kJ} / \mathrm{mol}$ ), with the overall reaction energy being exothermic $(-32 \mathrm{~kJ} / \mathrm{mol})$. This energy barrier is significantly lower than the first dehydrogenation step $(73 \mathrm{~kJ} / \mathrm{mol})$, while also lower than the corresponding step over $\operatorname{Pt}(111)$ $(79 \mathrm{~kJ} / \mathrm{mol})$. However, the breaking of the $\mathrm{C}_{\mathrm{alkyl}} \mathrm{O}$ bond to form $\mathrm{CH}_{2} *$ and the phenoxy intermediate is also very easy, with a barrier of only $24 \mathrm{~kJ} / \mathrm{mol}$ and a very exothermic reaction energy, $-127 \mathrm{~kJ} / \mathrm{mol}$. By contrast, the activation of the $\mathrm{C}_{\text {aryl }} \mathrm{O}$ bond that would lead to a phenyl intermediate and benzene as primary product has a somewhat higher barrier $(89 \mathrm{~kJ} / \mathrm{mol})$. While none of these paths has a very high barrier, the one which seems to dominate on $\mathrm{Ru}$ is the dehydrogenation of $\mathrm{Ph}-\mathrm{O}-\mathrm{CH}_{2} *$ to $\mathrm{Ph}-\mathrm{O}-\mathrm{CH}^{*}$.

Similarly, the three possible paths, $\mathrm{C}_{\text {alkyl }}-\mathrm{O}$ and $\mathrm{C}_{\text {aryl }} \mathrm{O}$ bond breaking, and continuing dehydrogenation were also calculated for the $\mathrm{Ph}-\mathrm{O}-\mathrm{CH}^{*}$ intermediate, as shown in Figure 9. Among the three options, the $\mathrm{C}_{\text {alkyl- }} \mathrm{O}$ bond breaking was the one with the lowest barrier (51 $\mathrm{kJ} / \mathrm{mol})$, while both the $\mathrm{C}_{\text {aryl }} \mathrm{O}$ bond breaking $(121 \mathrm{~kJ} / \mathrm{mol})$ and finally dehydrogenation (88 $\mathrm{kJ} / \mathrm{mol}$ ) are subject to significantly higher activation energies.

According to this analysis, we propose that on $\mathrm{Ru}(0001)$ the $\mathrm{HDO}$ of anisole starts with two 
sequential dehydrogenation steps on the $-\mathrm{CH}_{3}$ side group to form a $\mathrm{Ph}-\mathrm{O}-\mathrm{CH}^{*}$ intermediate, which then breaks the $\mathrm{C}_{\text {alkyl }}-\mathrm{O}$ bond to form a phenoxy intermediate. This pathway is consistent with previous DFT calculations of guaiacol on $\mathrm{Ru}(0001)$ that show catecholate is formed by $\mathrm{C}_{\text {alkyl }} \mathrm{O}$ breaking of a $* \mathrm{OPh}-\mathrm{O}-\mathrm{CH}^{*}$ intermediate $[52,53]$. It may also be noted in Fig. 9 that the energy barrier for breaking the $\mathrm{C}_{\mathrm{alkyl}} \mathrm{O}$ bond of the $\mathrm{Ph}-\mathrm{O}-\mathrm{CH}_{2} *$ intermediate is comparable enough $(24 \mathrm{~kJ} / \mathrm{mol})$ to occur in parallel. Thus, the phenoxy intermediate may also formed from $\mathrm{Ph}-\mathrm{O}-\mathrm{CH}_{2}{ }^{*}$. Similar to the behavior predicted for $\mathrm{Pt}$, the surface phenoxy is a crucial intermediate on $\mathrm{Ru}(0001)$ and the product selectivity should be determined by the fate of this intermediate. It can undergo hydrogenation to form phenol or $\mathrm{C}-\mathrm{O}$ bond cleavage to form a surface-bound phenyl species, as shown in Figure 7. The activation energy for the former is 134 $\mathrm{kJ} / \mathrm{mol}$, about $117 \mathrm{~kJ} / \mathrm{mol}$ higher than the same step on $\operatorname{Pt}(111)$ and very endothermic with a reaction energy of $89 \mathrm{~kJ} / \mathrm{mol}$, as opposed to the exothermic value obtained over $\operatorname{Pt}(111)(-22$ $\mathrm{kJ} / \mathrm{mol}$ ). The higher energy barrier and reaction energy calculated for hydrogenation of the phenoxyl oxygen on $\mathrm{Ru}(0001)$ is due to the strong interaction of oxygen with the metal. This is consistent with our previously reported trend for hydrogenation of the ketone tautomer of mcresol over $\operatorname{Ru}(0001)$ and $\operatorname{Pt}(111)$ surfaces [9, 80]. As a result, one would not expect a very high selectivity towards phenol on Ru catalyst, which is confirmed experimentally. Still, the phenoxy intermediate could cleave the $\mathrm{C}_{\text {aryl }} \mathrm{O}$ bond to form $\mathrm{O}^{*}$ and a phenyl intermediate, which can undergo hydrogenation to form benzene. In fact, the calculated energy barrier for this deoxygenation step to phenyl and $\mathrm{O}^{*}$ is $165 \mathrm{~kJ} / \mathrm{mol}$, which due to the stronger oxophilicity of $\mathrm{Ru}$ is about $105 \mathrm{~kJ} / \mathrm{mol}$ lower than that over $\mathrm{Pt}(111)$. This result is consistent with the demethoxylation reaction of anisole discussed above and the dehydroxylation of m-cresol reported previously over $\mathrm{Pt}(111)$ and $\mathrm{Ru}(0001)$ surfaces [9]. The energy diagrams for the hydrogenation and deoxygenation pathways of phenoxy to phenol and benzene are shown in Figure $8 \mathrm{~B}$. It can be concluded that after phenol is formed by hydrogenation of the phenoxy intermediate on $\mathrm{Ru}(0001)$, it may be difficult to desorb since the binding energy is $-260 \mathrm{~kJ} / \mathrm{mol}$ (Table 3). While entropy plays important roles in the desorption process, the adsorption free energy $(\Delta \mathrm{G})$ of phenol on $\mathrm{Ru}(0001)$ at $375{ }^{\circ} \mathrm{C}$ is still highly negative $-110 \mathrm{~kJ} / \mathrm{mol}$ (Table 3 ). Thus, although the energy barrier for the hydrogenation of the phenoxy intermediate to form phenol $(134 \mathrm{~kJ} / \mathrm{mol})$ is lower than the barrier for its deoxygenation to form phenyl intermediate on $\mathrm{Ru}(0001)$, due to the extreme endothermicity of the hydrogenation step $(89 \mathrm{~kJ} / \mathrm{mol})$ and the 
strong binding of phenol on $\mathrm{Ru}(0001)$ surface, the total barrier for the gas phase phenol formation is still higher than the deoxygenation path to form benzene, as shown in Figure 8B. However, as previously shown, the $\mathrm{O}^{*}$ formed during the HDO reaction may build up on the $\mathrm{Ru}$ surface due to its difficulty to be removed; hence, the energetics for hydrogenation and deoxygenation of the phenoxy intermediate may change as a function of conversion [9]. The results of the calculations for the hydrogenation of the surface species $\mathrm{O}^{*}$ and $\mathrm{OH}^{*}$ on $\mathrm{Ru}(0001)$ are summarized in the supplemental information (Figure S3). It is found that hydrogenation of both $\mathrm{O}^{*}$ and $\mathrm{OH}^{*}$ are very endothermic $(70 \mathrm{~kJ} / \mathrm{mol}$ and $50 \mathrm{~kJ} / \mathrm{mol})$ and involve high energy barriers (145 kJ/mol and $128 \mathrm{~kJ} / \mathrm{mol}$, respectively). Therefore, we have calculated the hydrogenation and deoxygenation of phenoxy in the presence of a moderate oxygen coverage, 7/16 ML O* on $\mathrm{Ru}(0001)$ surface, as shown in Figure 10. It is observed that on the $\mathrm{O}^{*}$-covered $\mathrm{Ru}(0001)$ surface, the hydrogenation reaction of phenoxy is facilitated, lowering the energy barrier and making the reaction less endothermic (103 and $29 \mathrm{~kJ} / \mathrm{mol}$, respectively) in comparison to those over the clean $\mathrm{Ru}(0001)$ surface (134 and $89 \mathrm{~kJ} / \mathrm{mol}$, respectively). In contrast, the deoxygenation reaction of phenoxy is hindered on the $\mathrm{O}^{*}$ covered $\mathrm{Ru}(0001)$ surface. Indeed, the energy barrier becomes higher and the reaction energy more endothermic (182 and $42 \mathrm{~kJ} / \mathrm{mol}$, respectively). Clearly, the energy diagram also shown in Figure 10 for the hydrogenation and deoxygenation paths of phenoxy on $\mathrm{O}^{*}$ covered $\mathrm{Ru}(0001)$ surface demonstrates that the hydrogenation path to release phenol is more favorable. This result correlates well with the results of the conversion of guaiacol over $\mathrm{Ru}(0001)$ that show that once catecholate $\left(\mathrm{C}_{6} \mathrm{H}_{4} \mathrm{O}_{2}\right)$ is formed, it undergoes hydrogenation to form catechol $\mathrm{C}_{6} \mathrm{H}_{4}(\mathrm{OH})_{2}$ or a $\mathrm{C}_{6} \mathrm{H}_{4}(\mathrm{O})(\mathrm{OH})$ intermediate before the dehydroxylation to $\mathrm{C}_{6} \mathrm{H}_{4} \mathrm{O}$ that yields phenol and benzene $[52,81]$. Thus, over Ru catalyst, benzene may result from both the direct deoxygenation of the phenoxy intermediate and/or further HDO of phenol as a secondary product. It is worth noting that the phenyl intermediate $\left(\mathrm{C}_{6} \mathrm{H}_{5}\right)$ that is converted into benzene is in fact a crucial intermediate in the reaction that can also lead to cracking products, as discussed in our previous work [9]. In this case, cracking will proceed by either further activating $\mathrm{C}-\mathrm{H}$ bonds to generate $\mathrm{C}_{6} \mathrm{H}_{\mathrm{y}}(\mathrm{x}<5)$ species or cleaving $\mathrm{C}-\mathrm{C}$ bonds to form $\mathrm{C}_{\mathrm{x}} \mathrm{H}_{\mathrm{y}}(\mathrm{x}<6, \mathrm{y}<5)$ species and $\mathrm{CH}$ species, similar to benzene decomposition observed on $\operatorname{Ir}(111)$ surfaces [82].

\subsection{Reaction paths for HDO of anisole over Fe(110)}


The same set of reaction pathways described for $\mathrm{Pt}$ and $\mathrm{Ru}$ were analyzed over $\mathrm{Fe}(110)$, as shown in Figure 11. Over the oxophilic $\mathrm{Fe}(110)$ the $\mathrm{C}_{\text {aryl }} \mathrm{O}$ bond breaking of anisole is very exothermic $(-124 \mathrm{~kJ} / \mathrm{mol})$ and it has a lower activation energy $(79 \mathrm{~kJ} / \mathrm{mol})$ than those calculated for $\mathrm{Pt}(111)$ and $\mathrm{Ru}(0001)$, i.e. 258 and $99 \mathrm{~kJ} / \mathrm{mol}$, respectively. Similarly, the activation energy for the $\mathrm{C}_{\mathrm{alkyl}} \mathrm{O}$ bond breaking of anisole over $\mathrm{Fe}(110)$ of $103 \mathrm{~kJ} / \mathrm{mol}$ is the lowest among the three metals. However, these two paths are still less favorable than the dehydrogenation of anisole at the $-\mathrm{CH}_{3}$ side group to form $\mathrm{Ph}-\mathrm{O}-\mathrm{CH}_{2} *$ over $\mathrm{Fe}(110)(70 \mathrm{~kJ} / \mathrm{mol})$. This suggests that dehydrogenation is still the most favorable initial step over $\mathrm{Fe}(110)$, similar to $\operatorname{Pt}(111)$ and $\mathrm{Ru}(0001)$, although the direct demethoxylation $\left(\mathrm{C}_{\text {aryl }}-\mathrm{O}\right.$ bond breaking $)$ becomes more competitive due to the stronger oxophilicity of Fe.

Similar to the behavior on $\mathrm{Pt}(111)$ and $\mathrm{Ru}(0001)$ surfaces, the removal of $\mathrm{H}$ atoms from the $\mathrm{CH}_{3}$ substituent facilitates both $\mathrm{C}_{\text {aryl }} \mathrm{O}$ and $\mathrm{C}_{\text {alkyl }} \mathrm{O}$ bond breaking over $\mathrm{Fe}(110)$. The barrier for the $\mathrm{C}_{\text {alkyl }} \mathrm{O}$ bond cleavage in $\mathrm{Ph}-\mathrm{O}-\mathrm{CH}_{2}{ }^{*}$ is only $17 \mathrm{~kJ} / \mathrm{mol}$, which is particularly low suggesting the $\mathrm{C}_{\text {alkyl }} \mathrm{O}$ bond breaking to form $\mathrm{CH}_{2} *$ and the phenoxy intermediate is the most favorable path for $\mathrm{Ph}-\mathrm{O}-\mathrm{CH}_{2}{ }^{*}$. The barrier for successive dehydrogenation of $\mathrm{Ph}-\mathrm{O}-\mathrm{CH}_{2} *$ to $\mathrm{Ph}-\mathrm{O}-\mathrm{CH}^{*}$ is also low $(32 \mathrm{~kJ} / \mathrm{mol})$, suggesting that it may also happen. Although being generated by a different reaction path relative to $\mathrm{Pt}(111)$ and $\mathrm{Ru}(0001)$, the formation of the phenoxy intermediate is still favored on $\mathrm{Fe}(110)$. This is consistent with the experimental observations that no $\mathrm{CH}_{3} \mathrm{OH}$, rather only $\mathrm{CH}_{4}$, is formed over the $\mathrm{Fe} / \mathrm{SiO}_{2}$ and $\mathrm{Pt} / \mathrm{Fe}_{2} \mathrm{O}_{3}$ catalysts . However, the major difference is the fate of the phenoxy intermediate after is formed on Fe(110). As mentioned above, it can undergo hydrogenation to phenol, or cleavage of the $\mathrm{C}-\mathrm{O}$ bond. As shown in Figure 7, the energy barrier for hydrogenation is relatively high $(147 \mathrm{~kJ} / \mathrm{mol})$, but the cleavage of the $\mathrm{C}_{\text {aryl- }} \mathrm{O}$ bond to form the phenyl group is much lower $(101 \mathrm{~kJ} / \mathrm{mol})$. That is, the deoxygenation path toward benzene is more favorable than the hydrogenation path toward phenol over $\mathrm{Fe}(110)$, and benzene instead of phenol should be the primary product from the HDO of anisole over Fe catalysts as shown in the energy diagram in Figure 8C. Similarly, we also calculated the deoxygenation and hydrogenation of the phenoxy intermediates over Fe(110) with a moderate 7/16 ML O* coverage in Figure 12, as the removal of $\mathrm{O}^{*}$ on $\mathrm{Fe}(110)$ is even more difficult than $\mathrm{Ru}(0001)$ as shown in Figure S3. On the Fe(110) surface with $7 / 16$ O* coverage, the energy barrier for the deoxygenation of the phenoxy intermediate to form the phenyl group increases slightly to $110 \mathrm{~kJ} / \mathrm{mol}$ while the energy barrier for the hydrogenation of it to form phenol 
decreases to $125 \mathrm{~kJ} / \mathrm{mol}$, similar to that on $\mathrm{Ru}(0001)$. This observation suggests that the preference of the $\mathrm{Fe}(110)$ surface to deoxygenation over hydrogenation of the phenoxy intermediate holds for a rather wide range of $\mathrm{O}^{*}$ coverages. This prediction is in fact validated by the experimental observations, showing the complete absence of phenol from the $\mathrm{Fe} / \mathrm{SiO}_{2}$ catalyst, even at the lowest conversions investigated.

As a general trend, it is interesting to compare the important effect of oxophilicity on the different reactions involved in HDO. As summarized in Figure 13, the intrinsic energy barriers for the direct deoxygenation of phenoxy via $\mathrm{C}_{\text {aryl }}-\mathrm{O}$ bond cleavage over different metal surfaces decrease with the binding energy of the atomic $\mathrm{O}$ to these metals, while those for hydrogenating the surface phenoxy increase. Therefore, while on Fe is more favorable for the phenoxy intermediate to break its $\mathrm{C}_{\text {aryl- }} \mathrm{O}$ bond than hydrogenating to form phenol the opposite is true on Pt. It must be noted that the correlation between HDO activity and oxophilicity of $\mathrm{Pt}, \mathrm{Ru}$ and $\mathrm{Fe}$ is also valid for the binding energies of carbon on the three metals (Table 3). Clearly, both can be attributed to the position of the $\mathrm{d}$ band center of the three metals, as shown in Table 3 . That is, the closer is the $\mathrm{d}$ band center to the Fermi level the higher are both $\mathrm{C}-\mathrm{M}$ and $\mathrm{O}-\mathrm{M}$ bond strengths. Table 4 summarizes the DFT calculated reaction energies and activation barriers for all the reaction steps investigated. All the trends discussed above are clearly evident in this table.

\section{Conclusion}

In this work, the conversion of anisole at $375^{\circ} \mathrm{C}$ under $\mathrm{H}_{2}$ flow at atmospheric pressure has been compared over $\mathrm{SiO}_{2}$-supported $\mathrm{Pt}, \mathrm{Ru}$, and $\mathrm{Fe}$ catalysts. Over $\mathrm{Pt} / \mathrm{SiO}_{2}$, phenol and benzene are produced sequentially. Thus, the selectivity of benzene increases at the expense of phenol as conversion increases. Over a more oxophilic catalyst as $\mathrm{Ru} / \mathrm{SiO}_{2}$, the trend is similar, but phenol is observed in lower yields while benzene increases with conversion. Over this catalyst, significant amounts of $\mathrm{CH}_{4}$ are produced by cracking. Over $\mathrm{Fe} / \mathrm{SiO}_{2}$, the most oxophilic catalyst investigated, benzene is the major product. Moreover, the most dramatic difference with the other metals is the complete absence of phenol in the products even at low conversions.

DFT calculations were carried out to explore the mechanism of these reactions and understand how the oxophilicity of the metal influences the reaction pathways. It was found that on all three metals, the dehydrogenation at the $-\mathrm{CH}_{3}$ side group is the most favorable reaction before any $\mathrm{C}-\mathrm{O}$ bond breaking. Removal of the $\mathrm{H}$ atoms at the $-\mathrm{CH}_{3}$ side group facilitates the 
subsequent $\mathrm{C}-\mathrm{O}$ bond breaking, especially the aliphatic $\mathrm{C}_{\text {alkyl }}-\mathrm{O}$ breaking. The surface phenoxy formed by this C-O cleavage can either undergo hydrogenation to form phenol as a primary product or break the $\mathrm{C}_{\text {aryl- }} \mathrm{O}$ bond to form the surface phenyl that leads finally to benzene via hydrogenation. The former dominates on $\mathrm{Pt}$ and to a certain extent on $\mathrm{Ru}$, over which phenol is the primary product from anisole conversion, but the latter is definitely dominant on $\mathrm{Fe}$, which explains why no phenol is observed from this catalyst.

\section{Acknowledgement}

We thank BP Corporation and the U.S. Department of Energy, DOE/EPSCOR (Grant DESC0004600) for funding. We also thank Supercomputing Center for Education and Research at University of Oklahoma (OSCER) and Extreme Science and Engineering Discovery Environment (XSEDE) for computational resources.

\section{References}

[1] G.H. Gu, C.A. Mullen, A.A. Boateng, D.G. Vlachos, Mechanism of Dehydration of Phenols on Noble Metals via First-Principles Microkinetic Modeling, ACS Catal., 6 (2016) 3047-3055. [2] M.B. Griffin, G.A. Ferguson, D.A. Ruddy, M.J. Biddy, G.T. Beckham, J.A. Schaidle, Role of the Support and Reaction Conditions on the Vapor-Phase Deoxygenation of $\mathrm{m}$-Cresol over Pt/C and Pt/TiO2 Catalysts, ACS Catal., (2016) 2715-2727.

[3] G.S. Foo, A.K. Rogers, M.M. Yung, C. Sievers, Steric Effect and Evolution of Surface Species in the Hydrodeoxygenation of Bio-Oil Model Compounds over Pt/HBEA, ACS Catal., (2016) 1292-1307.

[4] X. Zhu, L. Nie, L.L. Lobban, R.G. Mallinson, D.E. Resasco, Efficient Conversion of mCresol to Aromatics on a Bifunctional Pt/HBeta Catalyst, Energy Fuels, 28 (2014) 4104-4111.

[5] L. Nie, D.E. Resasco, Kinetics and mechanism of m-cresol hydrodeoxygenation on a Pt/SiO2 catalyst, J. Catal., 317 (2014) 22-29.

[6] L. Nie, P.M. de Souza, F.B. Noronha, W. An, T. Sooknoi, D.E. Resasco, Selective conversion of m-cresol to toluene over bimetallic Ni-Fe catalysts, J. Mol. Catal. A: Chem., 388-389 (2014) 47-55.

[7] P. de Souza, L. Nie, L.P. Borges, F. Noronha, D. Resasco, Role of Oxophilic Supports in the Selective Hydrodeoxygenation of m-Cresol on Pd Catalysts, Catal. Lett., 144 (2014) 2005-2011. [8] P.M. de Souza, R.C. Rabelo-Neto, L.E.P. Borges, G. Jacobs, B.H. Davis, T. Sooknoi, D.E. Resasco, F.B. Noronha, Role of Keto Intermediates in the Hydrodeoxygenation of Phenol over Pd on Oxophilic Supports, ACS Catal., 5 (2015) 1318-1329.

[9] Q. Tan, G. Wang, L. Nie, A. Dinse, C. Buda, J. Shabaker, D.E. Resasco, Different Product Distributions and Mechanistic Aspects of the Hydrodeoxygenation of m-Cresol over Platinum and Ruthenium Catalysts, ACS Catal., 5 (2015) 6271-6283.

[10] S. Pichaikaran, P. Arumugam, Vapour phase hydrodeoxygenation of anisole over ruthenium and nickel supported mesoporous aluminosilicate, Green Chem., 18 (2016) 2888-2899. 
[11] I.T. Ghampson, C. Sepulveda, A.B. Dongil, G. Pecchi, R. Garcia, J.L.G. Fierro, N. Escalona, Phenol hydrodeoxygenation: effect of support and Re promoter on the reactivity of Co catalysts, Catalysis Science \& Technology, 6 (2016) 7289-7306.

[12] A.L. Jongerius, R. Jastrzebski, P.C.A. Bruijnincx, B.M. Weckhuysen, CoMo sulfidecatalyzed hydrodeoxygenation of lignin model compounds- An extended reaction network for the conversion of monomeric and dimeric substrates, J. Catal., 285 (2012) 315-323.

[13] B. Yoosuk, D. Tumnantong, P. Prasassarakich, Unsupported MoS2 and CoMoS2 catalysts for hydrodeoxygenation of phenol, Chem. Eng. Sci., 79 (2012) 1-7.

[14] Y. Romero, F. Richard, S. Brunet, Hydrodeoxygenation of 2-ethylphenol as a model compound of bio-crude over sulfided Mo-based catalysts: Promoting effect and reaction mechanism, Appl. Catal., B, 98 (2010) 213-223.

[15] S.-K. Wu, P.-C. Lai, Y.-C. Lin, Atmospheric Hydrodeoxygenation of Guaiacol over Nickel Phosphide Catalysts: Effect of Phosphorus Composition, Catal. Lett., 144 (2014) 878-889.

[16] J.-S. Moon, E.-G. Kim, Y.-K. Lee, Active sites of Ni2P/SiO2 catalyst for hydrodeoxygenation of guaiacol: A joint XAFS and DFT study, J. Catal., 311 (2014) 144-152.

[17] D.J. Rensel, S. Rouvimov, M.E. Gin, J.C. Hicks, Highly selective bimetallic FeMoP catalyst for C-O bond cleavage of aryl ethers, J. Catal., 305 (2013) 256-263.

[18] H.Y. Zhao, D. Li, P. Bui, S.T. Oyama, Hydrodeoxygenation of guaiacol as model compound for pyrolysis oil on transition metal phosphide hydroprocessing catalysts, Appl. Catal., A, 391 (2011) 305-310.

[19] R.H. Bowker, M.C. Smith, M.L. Pease, K.M. Slenkamp, L. Kovarik, M.E. Bussell, Synthesis and Hydrodeoxygenation Properties of Ruthenium Phosphide Catalysts, ACS Catal., 1 (2011) 917-922.

[20] W.-S. Lee, Z. Wang, R.J. Wu, A. Bhan, Selective vapor-phase hydrodeoxygenation of anisole to benzene on molybdenum carbide catalysts, J. Catal., 319 (2014) 44-53.

[21] S. Boullosa-Eiras, R. Loedeng, H. Bergem, M. Stocker, L. Hannevold, E.A. Blekkan, Catalytic hydrodeoxygenation (HDO) of phenol over supported molybdenum carbide, nitride, phosphide and oxide catalysts, Catal. Today, 223 (2014) 44-53.

[22] S.-K. Wu, P.-C. Lai, Y.-C. Lin, H.-P. Wan, H.-T. Lee, Y.-H. Chang, Atmospheric Hydrodeoxygenation of Guaiacol over Alumina-, Zirconia-, and Silica-Supported Nickel Phosphide Catalysts, ACS Sustainable Chem. Eng., 1 (2013) 349-358.

[23] A.M. Robinson, J.E. Hensley, J.W. Medlin, Bifunctional Catalysts for Upgrading of Biomass-Derived Oxygenates: A Review, ACS Catal., 6 (2016) 5026-5043.

[24] Y. Hong, H. Zhang, J. Sun, K.M. Ayman, A.J.R. Hensley, M. Gu, M.H. Engelhard, J.-S. McEwen, Y. Wang, Synergistic Catalysis between Pd and Fe in Gas Phase Hydrodeoxygenation of m-Cresol, ACS Catal., (2014) 3335-3345.

[25] Z. Luo, Z. Zheng, Y. Wang, G. Sun, H. Jiang, C. Zhao, Hydrothermally stable Ru/HZSM-5catalyzed selective hydrogenolysis of lignin-derived substituted phenols to bio-arenes in water, Green Chem., 18 (2016) 5845-5858.

[26] H. Lee, H. Kim, M.J. Yu, C.H. Ko, J.-K. Jeon, J. Jae, S.H. Park, S.-C. Jung, Y.-K. Park, Catalytic Hydrodeoxygenation of Bio-oil Model Compounds over Pt/HY Catalyst, Sci. Rep., 6 (2016) 28765.

[27] K. Alharbi, W. Alharbi, E.F. Kozhevnikova, I.V. Kozhevnikov, Deoxygenation of Ethers and Esters over Bifunctional Pt-Heteropoly Acid Catalyst in the Gas Phase, ACS Catal., 6 (2016) 2067-2075.

[28] I. Yati, A.A. Dwiatmoko, J.S. Yoon, J.-W. Choi, D.J. Suh, J. Jae, J.-M. Ha, One-pot catalytic 
reaction to produce high-carbon-number dimeric deoxygenated hydrocarbons from ligninderived monophenyl vanillin using Al2O3-cogelled Ru nanoparticles, Appl. Catal., A, 524 (2016) 243-250.

[29] G.-Y. Xu, J.-H. Guo, Y.-C. Qu, Y. Zhang, Y. Fu, Q.-X. Guo, Selective hydrodeoxygenation of lignin-derived phenols to alkyl cyclohexanols over a Ru-solid base bifunctional catalyst, Green Chem., 18 (2016) 5510-5517.

[30] Q. Sun, G. Chen, H. Wang, X. Liu, J. Han, Q. Ge, X. Zhu, Insights into the Major Reaction Pathways of Vapor-Phase Hydrodeoxygenation of m-Cresol on a Pt/HBeta Catalyst, ChemCatChem, 8 (2016) 551-561.

[31] T.-S. Nguyen, D. Laurenti, P. Afanasiev, Z. Konuspayeva, L. Piccolo, Titania-supported gold-based nanoparticles efficiently catalyze the hydrodeoxygenation of guaiacol, J. Catal., 344 (2016) 136-140.

[32] P.T.M. Do, A.J. Foster, J. Chen, R.F. Lobo, Bimetallic effects in the hydrodeoxygenation of meta-cresol on $\gamma$-Al2O3 supported Pt-Ni and Pt-Co catalysts, Green Chem., 14 (2012) 13881397.

[33] R.N. Olcese, M. Bettahar, D. Petitjean, B. Malaman, F. Giovanella, A. Dufour, Gas-phase hydrodeoxygenation of guaiacol over Fe/SiO2 catalyst, Appl. Catal., B, 115-116 (2012) 63-73.

[34] Q. Lai, C. Zhang, J.H. Holles, Hydrodeoxygenation of guaiacol over Ni@Pd and Ni@Pt bimetallic overlayer catalysts, Appl. Catal., A, 528 (2016) 1-13.

[35] M. Kim, J.-M. Ha, K.-Y. Lee, J. Jae, Catalytic transfer hydrogenation/hydrogenolysis of guaiacol to cyclohexane over bimetallic RuRe/C catalysts, Catal. Commun., 86 (2016) 113-118.

[36] V.O.O. Goncalves, S. Brunet, F. Richard, Hydrodeoxygenation of Cresols Over Mo/Al2O3 and CoMo/Al2O3 Sulfided Catalysts, Catal. Lett., 146 (2016) 1562-1573.

[37] H. Fang, J. Zheng, X. Luo, J. Du, A. Roldan, S. Leoni, Y. Yuan, Product tunable behavior of carbon nanotubes-supported Ni-Fe catalysts for guaiacol hydrodeoxygenation, Appl. Catal., A, 529 (2017) 20-31.

[38] S.L. Yohe, H.J. Choudhari, D.D. Mehta, P.J. Dietrich, M.D. Detwiler, C.M. Akatay, E.A. Stach, J.T. Miller, W.N. Delgass, R. Agrawal, F.H. Ribeiro, High-pressure vapor-phase hydrodeoxygenation of lignin-derived oxygenates to hydrocarbons by a PtMo bimetallic catalyst: Product selectivity, reaction pathway, and structural characterization, J. Catal., 344 (2016) 535552.

[39] C.R. Lee, J.S. Yoon, Y.-W. Suh, J.-W. Choi, J.-M. Ha, D.J. Suh, Y.-K. Park, Catalytic roles of metals and supports on hydrodeoxygenation of lignin monomer guaiacol, Catal. Commun., 17 (2012) 54-58.

[40] I.T. Ghampson, C. Sepulveda, A.B. Dongil, G. Pecchi, R. Garcia, J.L.G. Fierro, N. Escalona, Phenol hydrodeoxygenation: effect of support and Re promoter on the reactivity of Co catalysts, Catal. Sci. Technol., 6 (2016) 7289-7306.

[41] A.B. Dongil, L. Pastor-Perez, A. Sepulveda-Escribano, R. Garcia, N. Escalona, Hydrodeoxygenation of guaiacol: Tuning the selectivity to cyclohexene by introducing Ni nanoparticles inside carbon nanotubes, Fuel, 172 (2016) 65-69.

[42] C. Zhang, J. Qi, J. Xing, S.-F. Tang, L. Song, Y. Sun, C. Zhang, H. Xin, X. Li, An investigation on the aqueous-phase hydrodeoxygenation of various methoxy-substituted lignin monomers on Pd/C and HZSM-5 catalysts, RSC Adv., 6 (2016) 104398-104406.

[43] A.J.R. Hensley, Y. Wang, J.-S. McEwen, Phenol Deoxygenation Mechanisms on Fe(110) and Pd(111), ACS Catal., 5 (2014) 523-536.

[44] J. Sun, A.M. Karim, H. Zhang, L. Kovarik, X.S. Li, A.J. Hensley, J.-S. McEwen, Y. Wang, 
Carbon-supported bimetallic Pd-Fe catalysts for vapor-phase hydrodeoxygenation of guaiacol, J. Catal., 306 (2013) 47-57.

[45] Y.-K. Hong, D.-W. Lee, H.-J. Eom, K.-Y. Lee, The catalytic activity of Pd/WOx/ $\gamma-\mathrm{Al} 2 \mathrm{O} 3$ for hydrodeoxygenation of guaiacol, Appl. Catal., B, 150-151 (2014) 438-445.

[46] M.A. Gonzalez-Borja, D.E. Resasco, Anisole and Guaiacol Hydrodeoxygenation over Monolithic Pt-Sn Catalysts, Energy Fuels, 25 (2011) 4155-4162.

[47] K. Lee, G.H. Gu, C.A. Mullen, A.A. Boateng, D.G. Vlachos, Guaiacol Hydrodeoxygenation Mechanism on Pt(111): Insights from Density Functional Theory and Linear Free Energy Relations, ChemSusChem, 8 (2015) 315-322.

[48] T. Nimmanwudipong, C. Aydin, J. Lu, R.C. Runnebaum, K.C. Brodwater, N.D. Browning, D.E. Block, B.C. Gates, Selective Hydrodeoxygenation of Guaiacol Catalyzed by Platinum Supported on Magnesium Oxide, Catal. Lett., 142 (2012) 1190-1196.

[49] D. Gao, C. Schweitzer, H.T. Hwang, A. Varma, Conversion of guaiacol on noble metal catalysts: reaction performance and deactivation studies, Ind. Eng. Chem. Res., 53 (2014) 18658. [50] K. Lee, G.H. Gu, C.A. Mullen, A.A. Boateng, D.G. Vlachos, Guaiacol Hydrodeoxygenation Mechanism on Pt(111): Insights from Density Functional Theory and Linear Free Energy Relations, ChemSusChem, 8 (2015) 315-322.

[51] S. Boonyasuwat, T. Omotoso, D. Resasco, S. Crossley, Conversion of Guaiacol over Supported Ru Catalysts, Catal. Lett., 143 (2013) 783-791.

[52] J. Lu, A. Heyden, Theoretical investigation of the reaction mechanism of the hydrodeoxygenation of guaiacol over a Ru(0001) model surface, J. Catal., 321 (2015) 39-50.

[53] C.-C. Chiu, A. Genest, A. Borgna, N. Rösch, Hydrodeoxygenation of Guaiacol over Ru(0001): A DFT Study, ACS Catal., 4 (2014) 4178-4188.

[54] R. Olcese, M.M. Bettahar, B. Malaman, J. Ghanbaja, L. Tibavizco, D. Petitjean, A. Dufour, Gas-phase hydrodeoxygenation of guaiacol over iron-based catalysts. Effect of gases composition, iron load and supports (silica and activated carbon), Appl. Catal., B, 129 (2013) 528-538.

[55] R.N. Olcese, J. Francois, M.M. Bettahar, D. Petitjean, A. Dufour, Hydrodeoxygenation of Guaiacol, A Surrogate of Lignin Pyrolysis Vapors, Over Iron Based Catalysts: Kinetics and Modeling of the Lignin to Aromatics Integrated Process, Energy Fuels, 27 (2013) 975-984.

[56] R.N. Olcese, G. Lardier, M. Bettahar, J. Ghanbaja, S. Fontana, V. Carre, F. Aubriet, D. Petitjean, A. Dufour, Aromatic Chemicals by Iron-Catalyzed Hydrotreatment of Lignin Pyrolysis Vapor, ChemSusChem, 6 (2013) 1490-1499.

[57] T. Omotoso, S. Boonyasuwat, S.P. Crossley, Understanding the role of $\mathrm{TiO} 2$ crystal structure on the enhanced activity and stability of $\mathrm{Ru} / \mathrm{TiO} 2$ catalysts for the conversion of ligninderived oxygenates, Green Chem., 16 (2014) 645-652.

[58] G.L. Haller, D.E. Resasco, Metal-Support Interaction: Group VIII Metals and Reducible Oxides, in: H.P. D.D. Eley, B.W. Paul (Eds.) Adv. Catal., Academic Press, 1989, pp. 173-235.

[59] X. Zhu, L.L. Lobban, R.G. Mallinson, D.E. Resasco, Bifunctional transalkylation and hydrodeoxygenation of anisole over a Pt/HBeta catalyst, J. Catal., 281 (2011) 21-29.

[60] S. Sitthisa, W. An, D.E. Resasco, Selective conversion of furfural to methylfuran over silicasupported NiFe bimetallic catalysts, J. Catal., 284 (2011) 90-101.

[61] Y.-H. Chin, C. Buda, M. Neurock, E. Iglesia, Selectivity of chemisorbed oxygen in C-H bond activation and $\mathrm{CO}$ oxidation and kinetic consequences for $\mathrm{CH} 4-\mathrm{O} 2$ catalysis on $\mathrm{Pt}$ and $\mathrm{Rh}$ clusters, J. Catal., 283 (2011) 10-24.

[62] G. Kresse, J. Hafner, Ab initio molecular dynamics for liquid metals, Phys. Rev. B, 47 (1993) 
558-561.

[63] G. Kresse, J. Hafner, Ab initio molecular-dynamics simulation of the liquid-metalamorphous-semiconductor transition in germanium, Phys. Rev. B, 49 (1994) 14251-14269.

[64] G. Kresse, J. Furthmüller, Efficiency of ab-initio total energy calculations for metals and semiconductors using a plane-wave basis set, Comput. Mater. Sci., 6 (1996) 15-50.

[65] G. Kresse, J. Furthmüller, Efficient iterative schemes for ab initio total-energy calculations using a plane-wave basis set, Phys. Rev. B, 54 (1996) 11169-11186.

[66] J.P. Perdew, K. Burke, M. Ernzerhof, Generalized Gradient Approximation Made Simple, Phys. Rev. Lett., 77 (1996) 3865-3868.

[67] S. Grimme, J. Antony, S. Ehrlich, H. Krieg, A consistent and accurate ab initio parametrization of density functional dispersion correction (DFT-D) for the 94 elements $\mathrm{H}-\mathrm{Pu}, \mathrm{J}$. Chem. Phys., 132 (2010) 154104.

[68] G. Kresse, D. Joubert, From ultrasoft pseudopotentials to the projector augmented-wave method, Phys. Rev. B, 59 (1999) 1758-1775.

[69] H.J. Monkhorst, J.D. Pack, Special points for Brillouin-zone integrations, Phys. Rev. B, 13 (1976) 5188-5192.

[70] G. Henkelman, H. Jónsson, A dimer method for finding saddle points on high dimensional potential surfaces using only first derivatives, J. Chem. Phys., 111 (1999) 7010-7022.

[71] G. Henkelman, H. Jónsson, Improved tangent estimate in the nudged elastic band method for finding minimum energy paths and saddle points, J. Chem. Phys., 113 (2000) 9978-9985.

[72] D.A. McQuarrie, J.D. Simon, Molecular Thermondynamics, University Science Books: Sausalito, 1999.

[73] H.-Y. Lin, Y.-W. Chen, C. Li, The mechanism of reduction of iron oxide by hydrogen, Thermochim. Acta, 400 (2003) 61-67.

[74] A.J.R. Hensley, Y. Hong, R. Zhang, H. Zhang, J. Sun, Y. Wang, J.-S. McEwen, Enhanced Fe2O3 Reducibility via Surface Modification with Pd: Characterizing the Synergy within Pd/Fe Catalysts for Hydrodeoxygenation Reactions, ACS Catal., 4 (2014) 3381-3392.

[75] A.J.R. Hensley, Y. Wang, J.-S. McEwen, Adsorption of phenol on Fe (110) and Pd (111) from first principles, Surf. Sci., 630 (2014) 244-253.

[76] M. Salciccioli, D.G. Vlachos, Kinetic Modeling of Pt Catalyzed and Computation-Driven Catalyst Discovery for Ethylene Glycol Decomposition, ACS Catal., 1 (2011) 1246-1256.

[77] J.E. Sutton, P. Panagiotopoulou, X.E. Verykios, D.G. Vlachos, Combined DFT, Microkinetic, and Experimental Study of Ethanol Steam Reforming on Pt, J. Phys. Chem. C, 117 (2013) 46914706.

[78] M. Chia, Y.J. Pagan-Torres, D. Hibbitts, Q. Tan, H.N. Pham, A.K. Datye, M. Neurock, R.J. Davis, J.A. Dumesic, Selective hydrogenolysis of polyols and cyclic ethers over bifunctional surface sites on rhodium-rhenium catalysts, J. Am. Chem. Soc., 133 (2011) 12675-12689.

[79] F. Viñes, Y. Lykhach, T. Staudt, M.P.A. Lorenz, C. Papp, H.-P. Steinrück, J. Libuda, K.M. Neyman, A. Görling, Methane Activation by Platinum: Critical Role of Edge and Corner Sites of Metal Nanoparticles, Chem. Eur. J., 16 (2010) 6530-6539.

[80] N.K. Sinha, M. Neurock, A first principles analysis of the hydrogenation of C1C4 aldehydes and ketones over Ru(0001), J. Catal., 295 (2012) 31-44.

[81] C.-C. Chiu, A. Genest, A. Borgna, N. Rosch, C-O cleavage of aromatic oxygenates over ruthenium catalysts. A computational study of reactions at step sites, Phys. Chem. Chem. Phys., 17 (2015) 15324-15330.

[82] C.J. Weststrate, J.W. Bakker, A.C. Gluhoi, W. Ludwig, B.E. Nieuwenhuys, Benzene 
adsorption and oxidation on $\operatorname{Ir}(111)$, Surf. Sci., 601 (2007) 748-756. 


\section{Table 1}

Summary of the characterization of the $\mathrm{Pt} / \mathrm{SiO}_{2}, \mathrm{Ru} / \mathrm{SiO}_{2}$ and $\mathrm{Fe} / \mathrm{SiO}_{2}$ catalysts

\begin{tabular}{cccc}
\hline & $\mathbf{P t} / \mathbf{S i O}_{2}$ & $\mathbf{R u} / \mathbf{S i O}_{2}$ & $\mathbf{F e} / \mathbf{S i O}_{2}$ \\
\hline Metal loading* & 1 wt. \% & 9 wt. \% & 5 wt. \% \\
\hline d $_{\mathbf{p}}$ & $3.5 \mathrm{~nm}$ & $5.2 \mathrm{~nm}$ & $23.4 \mathrm{~nm}$ \\
\hline Metal Dispersion & 0.3 & 0.25 & 0.05 \\
\hline
\end{tabular}

(*) different loadings were used due to the disparity in the intrinsic activity of the metals 


\section{Table 2}

Product distributions for the $\mathrm{HDO}$ of anisole over the $\mathrm{Pt} / \mathrm{SiO}_{2}, \mathrm{Ru} / \mathrm{SiO}_{2}, \mathrm{Fe} / \mathrm{SiO}_{2}$ and $\mathrm{Pt} / \mathrm{Fe}_{2} \mathrm{O}_{3}$ catalysts at $375^{\circ} \mathrm{C}$ and atmospheric pressure.

\begin{tabular}{|c|c|c|c|c|}
\hline & $\mathrm{Pt} / \mathrm{SiO}_{2}$ & $\mathrm{Ru} / \mathrm{SiO}_{2}$ & $\mathrm{Fe} / \mathrm{SiO}_{2}$ & $\mathrm{Pt} / \mathrm{Fe}_{2} \mathrm{O}_{3}$ \\
\hline W/F (gcat.hr/g) & 0.02 & 0.10 & 0.12 & 0.08 \\
\hline Conversion $(\%)$ & 15 & 5 & 8 & 7 \\
\hline TOF $\left(\min ^{-1}\right)$ & 75 & 0.4 & 2.3 & - \\
\hline \multicolumn{5}{|l|}{ Selectivity (\%) } \\
\hline Phenol & 93 & 9 & - & - \\
\hline Benzene & 7 & 16 & 85 & 80 \\
\hline $\mathrm{CH}_{4}$ from cracking & - & 75 & 6 & 7 \\
\hline Toluene & - & - & 9 & 13 \\
\hline $\mathrm{CH}_{4} /$ Aromatics & 1 & 22 & 1.4 & 1.5 \\
\hline
\end{tabular}




\section{Table 3}

Adsorption energies $(\mathrm{kJ} / \mathrm{mol})$ of reactant, products and intermediates in the hydrodeoxygenation of anisol on $\mathrm{Pt}(111), \mathrm{Ru}(0001)$ and $\mathrm{Fe}(110)$ surfaces.

\begin{tabular}{|c|c|c|c|c|c|c|}
\hline & \multicolumn{2}{|c|}{$P t(111)$} & \multicolumn{2}{c|}{$R \mathbf{R}(0001)$} & \multicolumn{2}{c|}{ Fe(110) } \\
\hline & $\Delta \mathrm{E}$ & $\Delta \mathrm{G}$ & $\Delta \mathrm{E}$ & $\Delta \mathrm{G}$ & $\Delta \mathrm{E}$ & $\Delta \mathrm{G}$ \\
\hline Anisole & -225 & - & -263 & - & -232 & - \\
\hline Phenol & -218 & -71 & -260 & -110 & -230 & -83 \\
\hline Benzene & -212 & -31 & -250 & -69 & -227 & -46 \\
\hline H & -43 & -4 & -54 & -14 & -70 & -30 \\
\hline O & -481 & - & -650 & - & -698 & - \\
\hline C & -692 & - & -740 & - & -826 & - \\
\hline d-band center & $-2.32 \mathrm{eV}$ & $-1.94 \mathrm{eV}$ & $-1.56 \mathrm{eV}$ \\
\hline
\end{tabular}

$(*)$ Free energies of adsorption $(\Delta \mathrm{G})$ were calculated at $375^{\circ} \mathrm{C}$ and $1 \mathrm{~atm}$. 


\section{Table 4}

Summary of the DFT calculated energetics $(\mathrm{kJ} / \mathrm{mol})$ of the elementary steps in the HDO of anisole over the $\mathrm{Pt}(111), \mathrm{Ru}(0001)$, and $\mathrm{Fe}(110)$ surfaces.

\begin{tabular}{|c|c|c|c|c|c|c|c|}
\hline \multicolumn{2}{|r|}{ Reactions } & \multicolumn{2}{|c|}{$\operatorname{Pt}(111)$} & \multicolumn{2}{|c|}{$\mathbf{R u}(\mathbf{0 0 0 1})$} & \multicolumn{2}{|c|}{$\operatorname{Fe}(110)$} \\
\hline & & $\mathrm{E}_{\mathrm{act}}$ & $\mathrm{E}_{\mathrm{rxn}}$ & $\mathrm{E}_{\mathrm{act}}$ & $\mathrm{E}_{\mathrm{rxn}}$ & $\mathrm{E}_{\mathrm{act}}$ & $\mathrm{E}_{\mathrm{rxn}}$ \\
\hline \multirow{3}{*}{ Dehydrogenation } & $\mathrm{Ph}-\mathrm{O}-\mathrm{CH}_{3} *+* \mathrm{Ph}-\mathrm{O}-\mathrm{CH}_{2} *+\mathrm{H}^{*}$ & 125 & 12 & 73 & -12 & 70 & -26 \\
\hline & $\mathrm{Ph}-\mathrm{O}-\mathrm{CH}_{2} *+* \leftrightarrow \mathrm{Ph}-\mathrm{O}-\mathrm{CH}^{*}+\mathrm{H}^{*}$ & 79 & -22 & 14 & -32 & 32 & -38 \\
\hline & $\mathrm{Ph}-\mathrm{O}-\mathrm{CH}^{*}+* \leftrightarrow \mathrm{Ph}-\mathrm{O}-\mathrm{C}^{*}+\mathrm{H}^{*}$ & 124 & 32 & 88 & -24 & 30 & -82 \\
\hline \multirow{3}{*}{$\mathrm{C}_{\text {aryl }} \mathrm{O}$ B Breaking } & $\mathrm{Ph}-\mathrm{O}-\mathrm{CH}_{3} *+* \leftrightarrow \mathrm{Ph}^{*}+\mathrm{OCH}_{3}^{*}$ & 258 & 147 & 99 & -63 & 79 & -124 \\
\hline & $\mathrm{Ph}-\mathrm{O}-\mathrm{CH}_{2} *+* \leftrightarrow \mathrm{Ph}^{*}+\mathrm{OCH}_{2}^{*}$ & 227 & 103 & 89 & -45 & 64 & -43 \\
\hline & $\mathrm{Ph}-\mathrm{O}-\mathrm{CH}^{*}+* \leftrightarrow \mathrm{Ph}^{*}+\mathrm{OCH}^{*}$ & 150 & 47 & 121 & -40 & 59 & -38 \\
\hline \multirow{3}{*}{$\mathrm{C}_{\text {alkyl }}-\mathrm{O}$ Breaking } & $\mathrm{Ph}-\mathrm{O}-\mathrm{CH}_{3} *+* \leftrightarrow \mathrm{Ph}-\mathrm{O} *+\mathrm{CH}_{3} *$ & 200 & -4 & 135 & -91 & 103 & -75 \\
\hline & $\mathrm{Ph}-\mathrm{O}-\mathrm{CH}_{2} *+* \leftrightarrow \mathrm{Ph}-\mathrm{O}^{*}+\mathrm{CH}_{2}^{*}$ & 90 & -7 & 24 & -127 & 17 & -117 \\
\hline & $\mathrm{Ph}-\mathrm{O}-\mathrm{CH}^{*}+* \leftrightarrow \mathrm{Ph}-\mathrm{O}^{*}+\mathrm{CH}^{*}$ & 83 & -49 & 51 & -154 & 16 & -166 \\
\hline \multirow{2}{*}{ Fate of $\mathrm{Ph}-\mathrm{O}^{*}$} & $\mathrm{Ph}-\mathrm{O}^{*}+\mathrm{H}^{*} \leftrightarrow \mathrm{Ph}-\mathrm{OH}^{*}+*$ & 17 & -22 & 134 & 89 & 147 & 103 \\
\hline & $\mathrm{Ph}-\mathrm{O}^{*}+* \leftrightarrow \mathrm{Ph}^{*}+\mathrm{O}^{*}$ & 270 & 140 & 165 & -11 & 101 & -42 \\
\hline
\end{tabular}


(A)

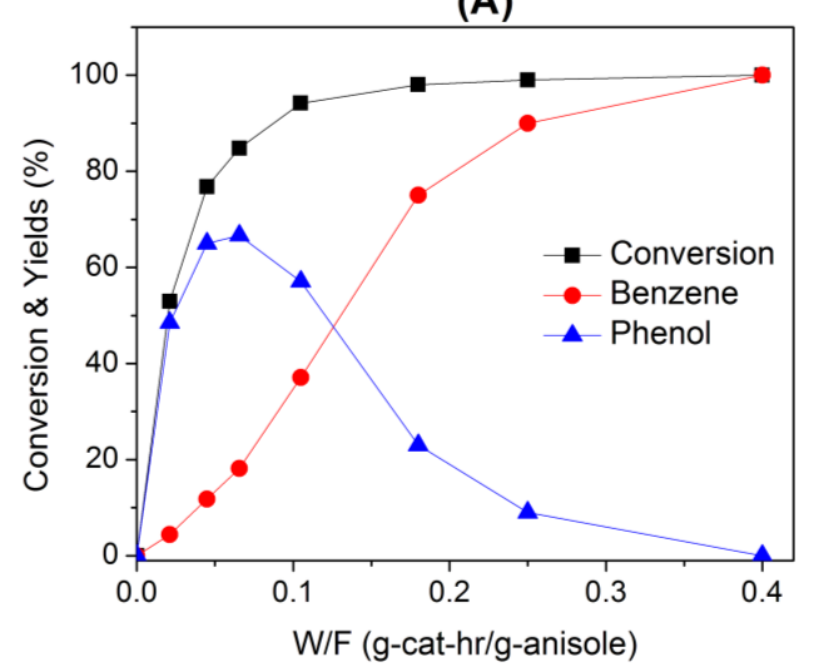

(B)

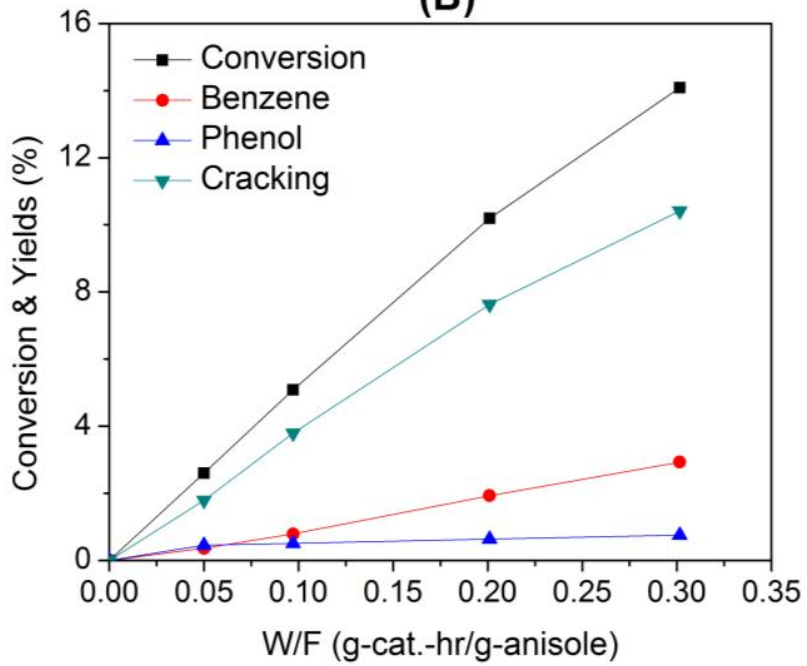

(C)

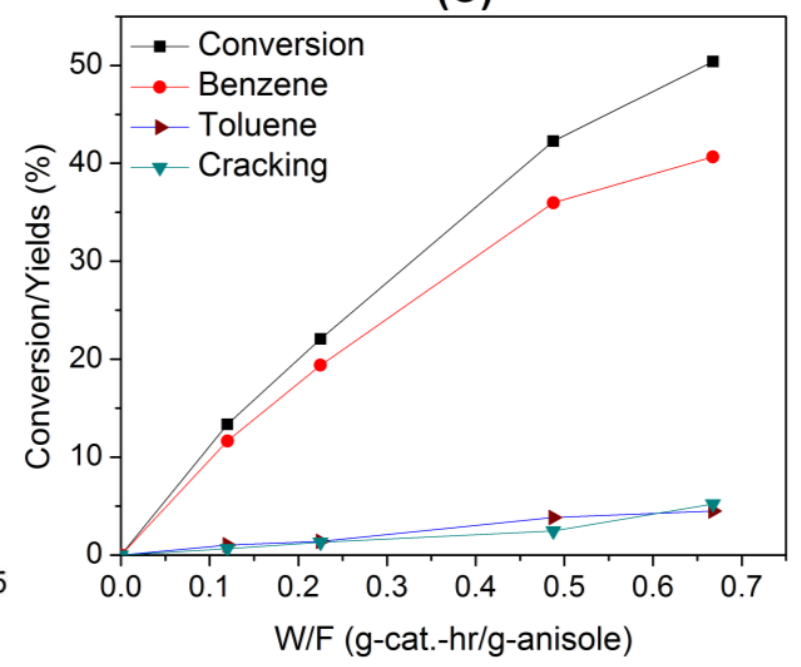

Fig. 1. Conversion and yields of products of $\mathrm{HDO}$ of anisole over $\mathrm{Pt} / \mathrm{SiO}_{2}(\mathrm{~A}), \mathrm{Ru} / \mathrm{SiO}_{2}(\mathrm{~B})$, and $\mathrm{Fe} / \mathrm{SiO}_{2}(\mathrm{C})$ as a function of $\mathrm{W} / \mathrm{F}$ at $375^{\circ} \mathrm{C}$ and atmospheric pressure 

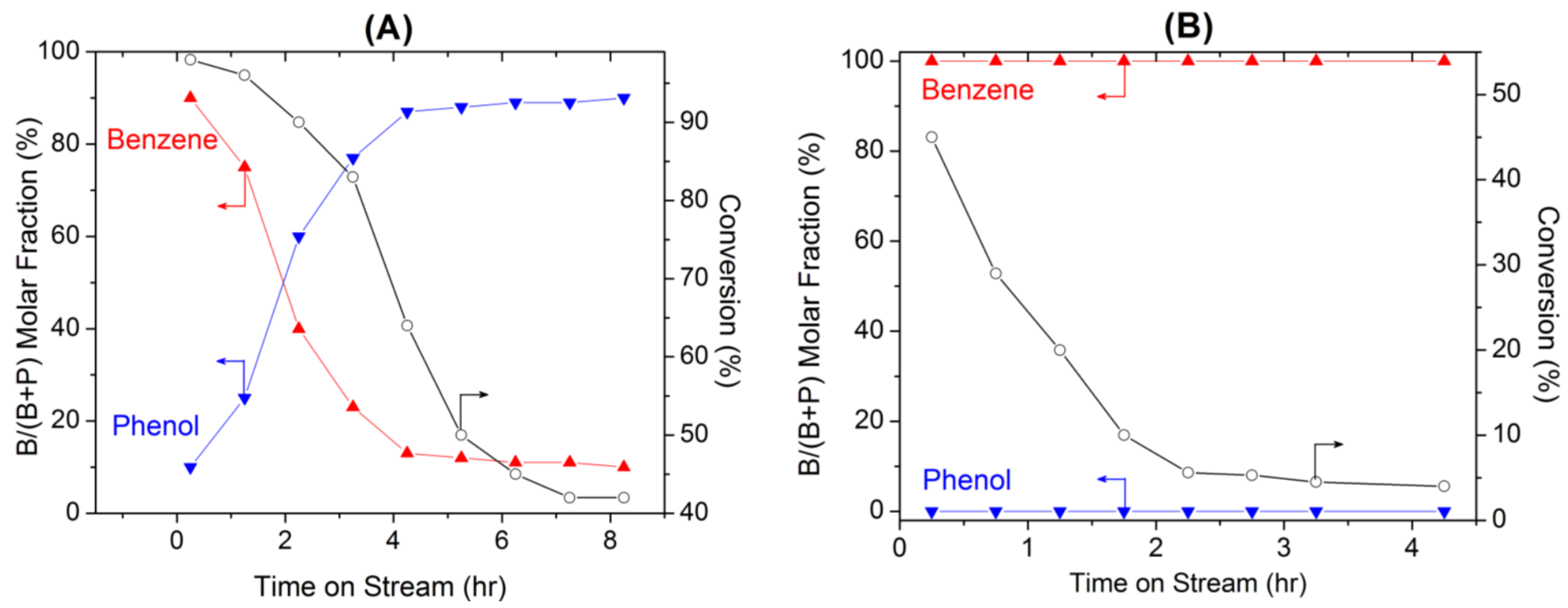

Fig. 2. Molar fraction of phenol and benzene in the products of HDO of anisole over $\mathrm{Pt} / \mathrm{SiO}_{2}(\mathrm{~A})$ and $\mathrm{Fe} / \mathrm{SiO}_{2}$ (B) with different time on stream at $375{ }^{\circ} \mathrm{C}$ and atmospheric pressure 

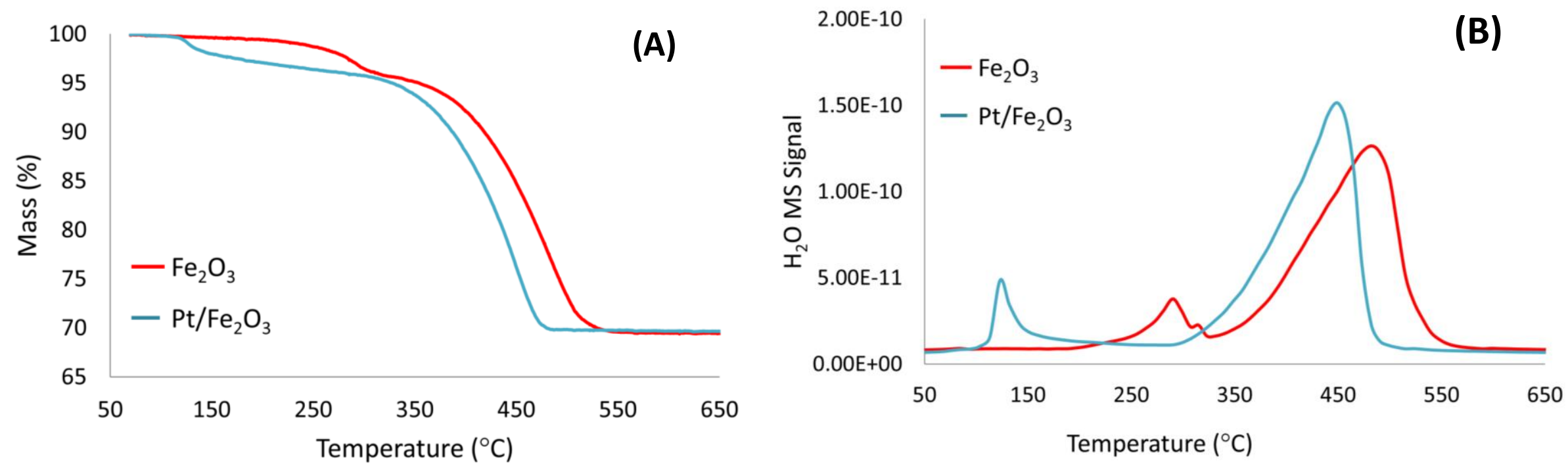

Fig. 3. Thermogravimetric analysis of $\mathrm{Fe}_{2} \mathrm{O}_{3}$ and $1 \% \mathrm{Pt} / \mathrm{Fe}_{2} \mathrm{O}_{3}$ with mass loss (A) and $\mathrm{H}_{2} \mathrm{O}$ mass spectrometry signal (B). 

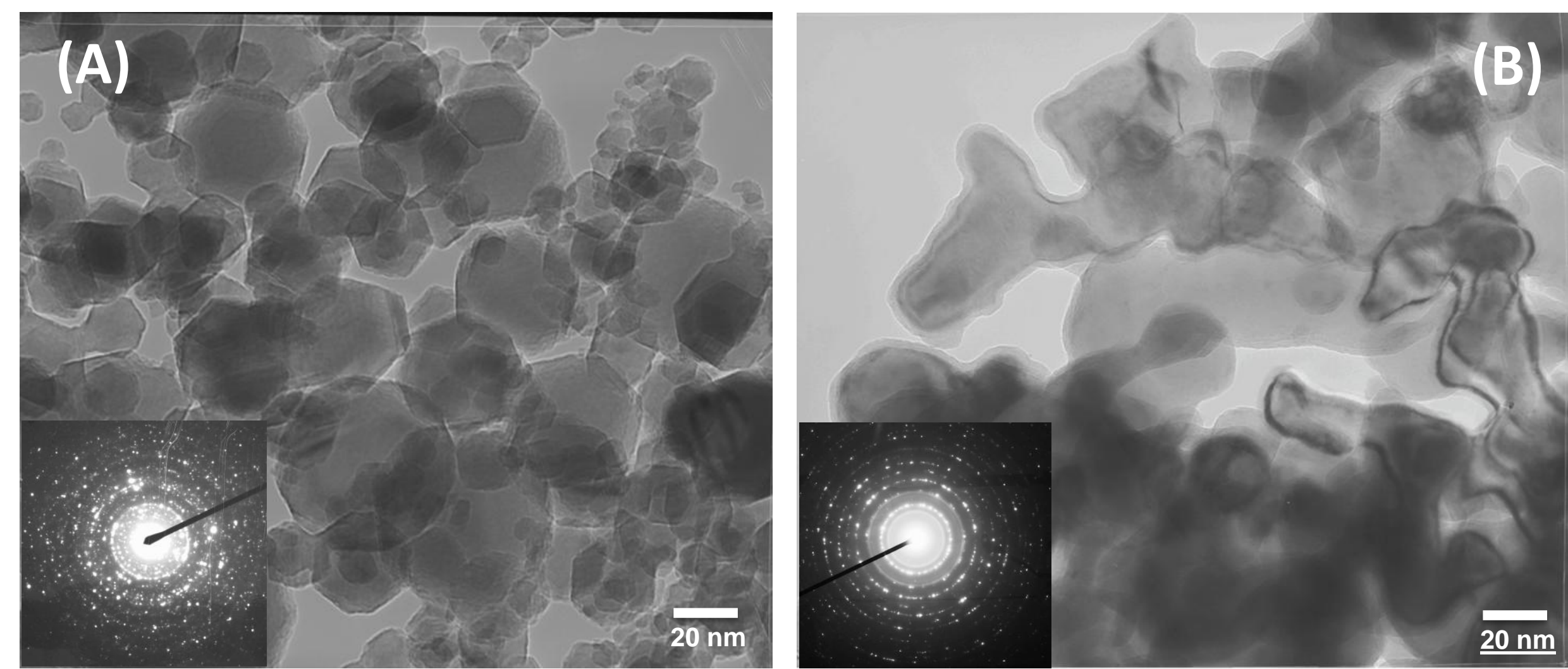

Fig. 4. TEM and electron diffraction patterns of (A) $\mathrm{Fe}_{2} \mathrm{O}_{3}$ before reduction; and (B) Pt-doped $\mathrm{Fe}_{2} \mathrm{O}_{3}$ after reduction. 

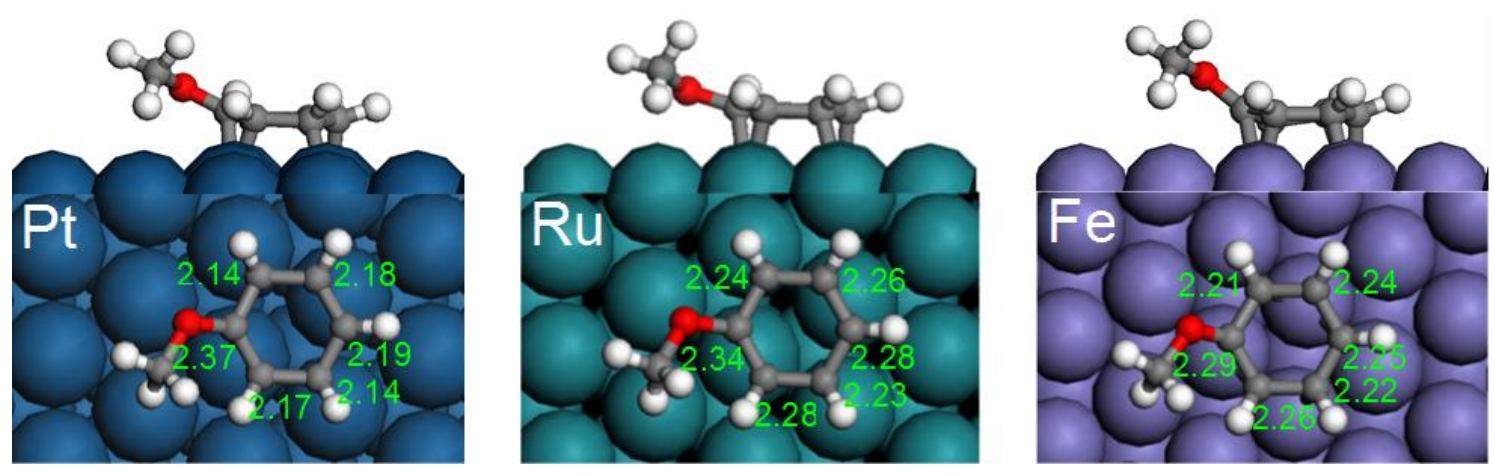

Fig. 5. DFT calculated adsorption configuration of anisole on $\operatorname{Pt}(111), \operatorname{Ru}(0001)$, and $\mathrm{Fe}(110)$ surfaces 

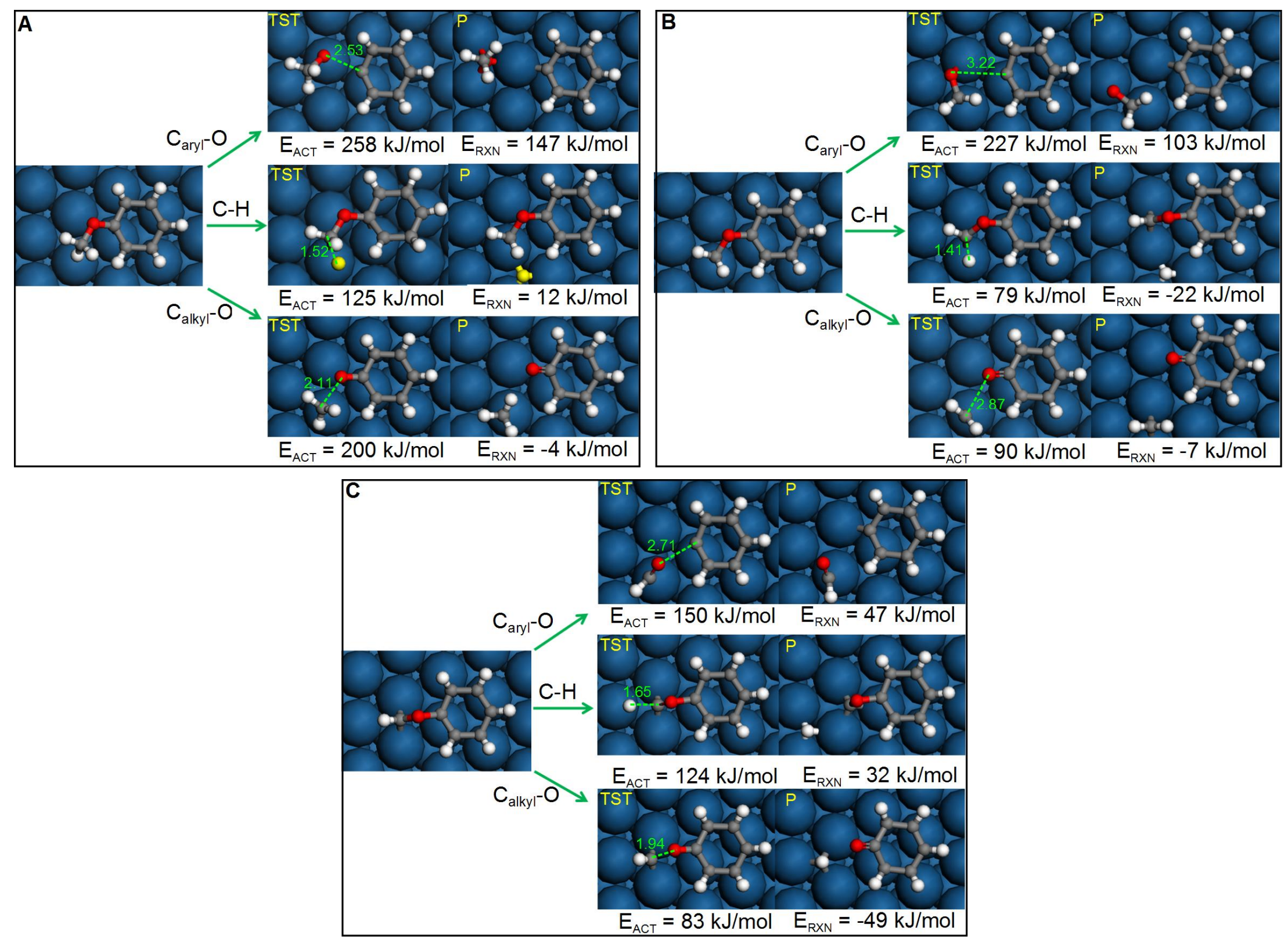

Fig. 6. DFT calculated reactant, transition state and product structures for the $\mathrm{C}_{\text {aryl }}-\mathrm{O}$ bond breaking, $\mathrm{C}_{\text {alkyl }} \mathrm{O}$ bond breaking and dehydrogenation reaction of different $\mathrm{Ph}-\mathrm{O}-\mathrm{CH}_{\mathrm{x}}(\mathrm{x}=1 \sim 3)$ intermediates over $\mathrm{Pt}(111)$. 


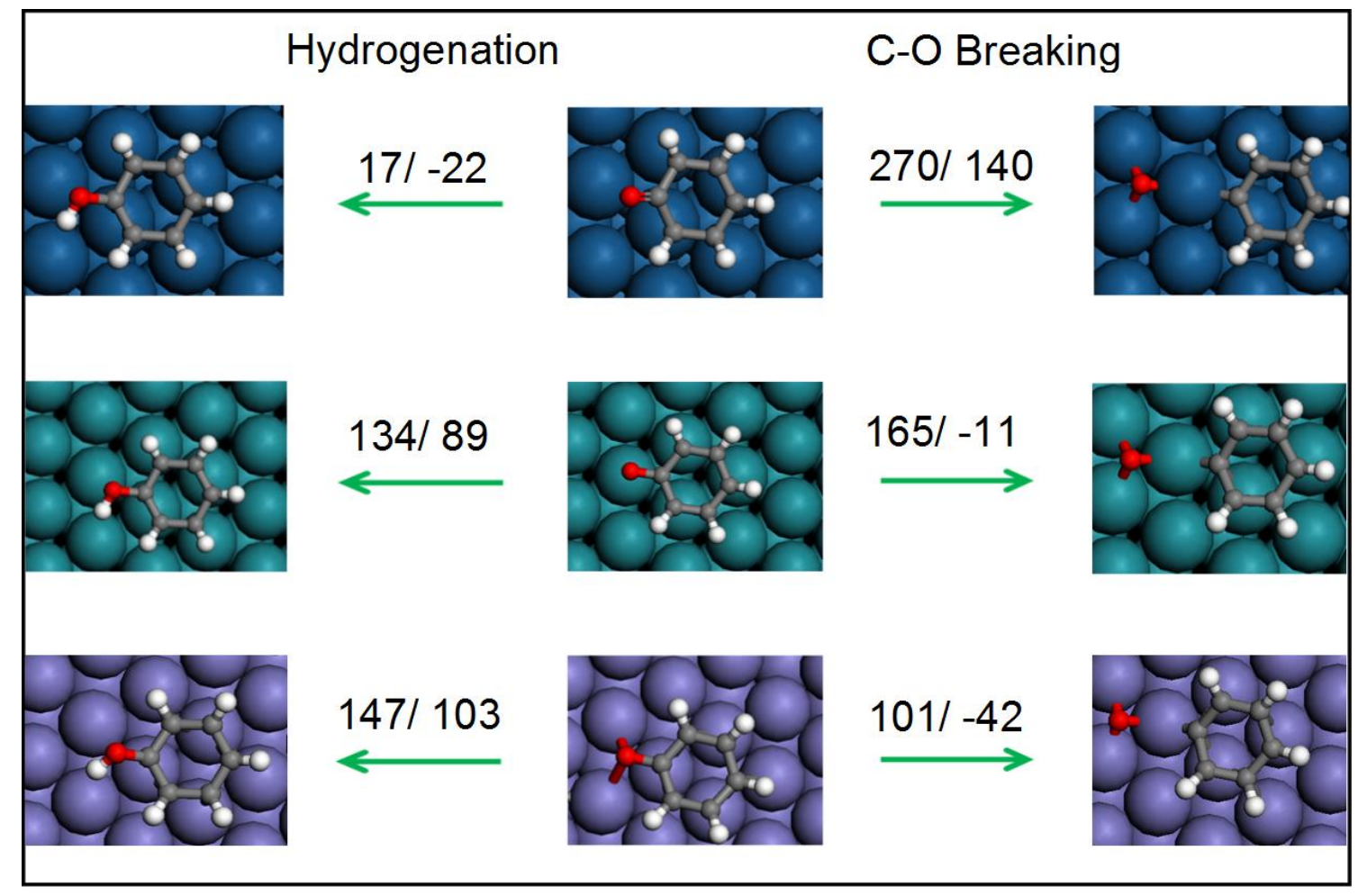

Fig. 7. DFT calculated reactant and product structures for the hydrogenation and deoxygenation of the phenoxy intermediate over $\operatorname{Pt}(111), \operatorname{Ru}(0001)$ and $\mathrm{Fe}(110)$ surfaces. The energetics $\left(\mathrm{E}_{\mathrm{ACT}} / \mathrm{E}_{\mathrm{RXN}}\right)$ are in $\mathrm{kJ} / \mathrm{mol}$. 


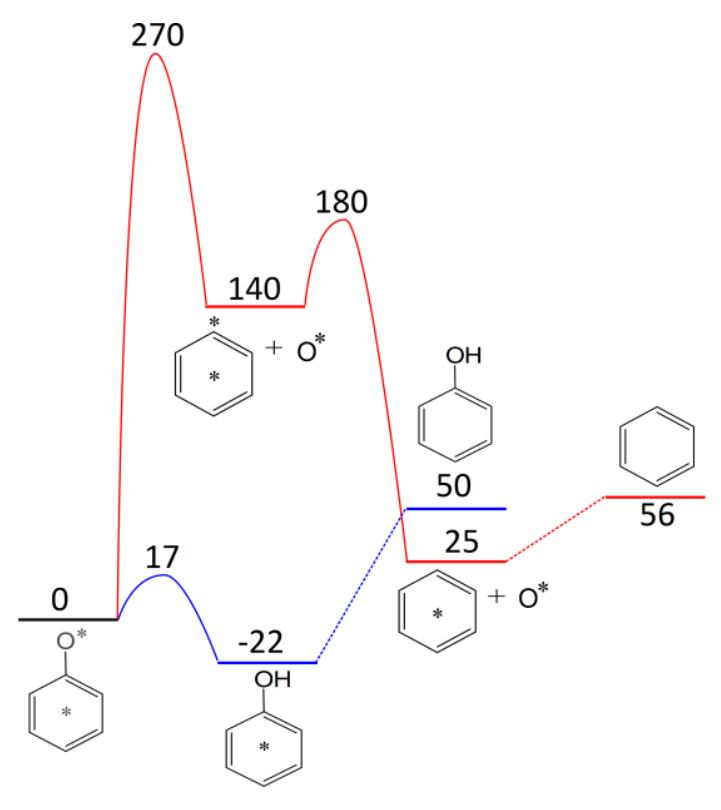

(A)

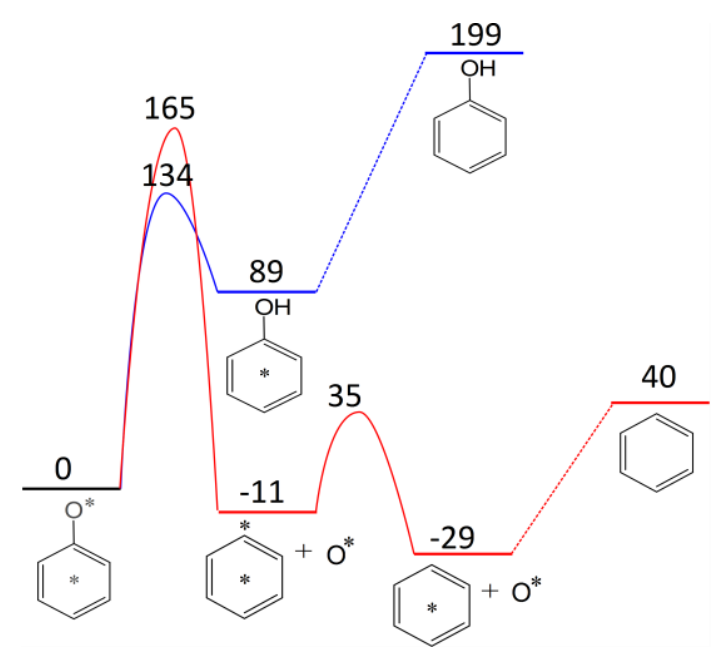

(B)

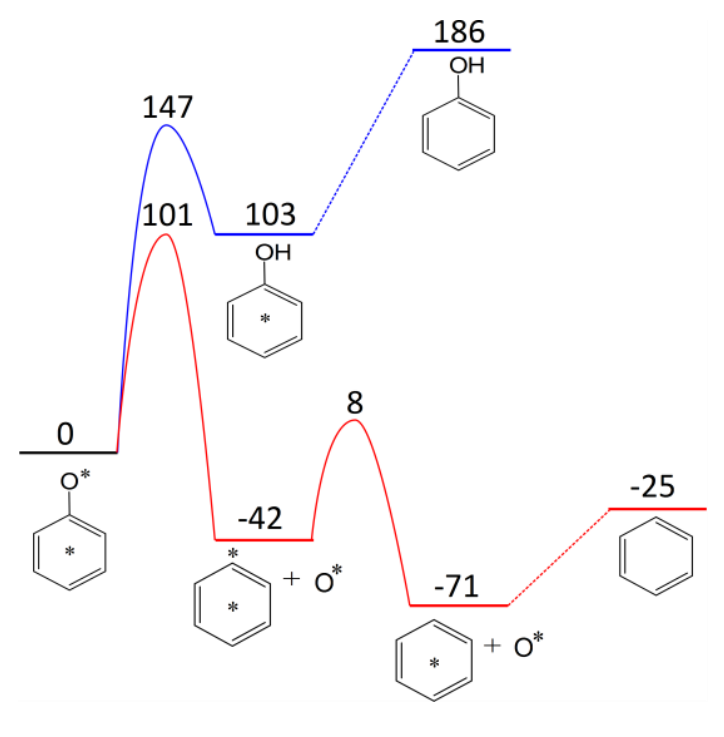

(C)

Fig. 8. Energy diagrams for the hydrogenation and deoxygenation of the phenoxy intermediate over $\operatorname{Pt}(111)(\mathrm{A}), \mathrm{Ru}(0001)(\mathrm{B})$ and $\mathrm{Fe}(110)(\mathrm{C})$. The energetics $\left(\mathrm{E}_{\mathrm{ACT}} / \mathrm{E}_{\mathrm{RXN}}\right)$ are in $\mathrm{kJ} / \mathrm{mol}$. 


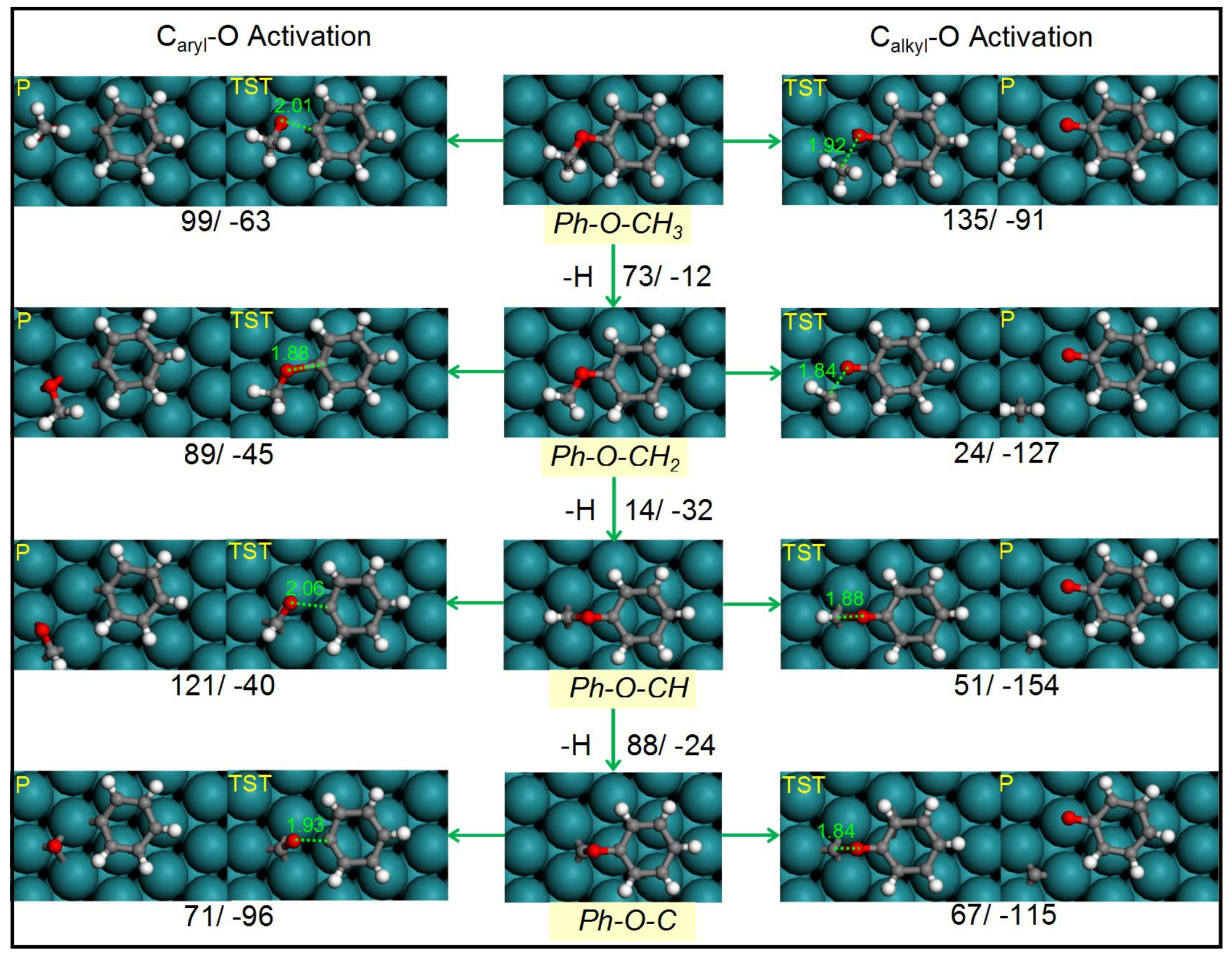

Fig. 9. DFT calculated reactant, transition state and product structures for the $\mathrm{C}_{\text {aryl }}-\mathrm{O}$ bond breaking, $\mathrm{C}_{\mathrm{alkyl}} \mathrm{O}$ bond breaking and dehydrogenation reactions of different $\mathrm{Ph}-\mathrm{O}-\mathrm{CH}_{\mathrm{x}}(\mathrm{x}=1 \sim 3)$ intermediates over $\mathrm{Ru}(0001)$. The energetics $\left(\mathrm{E}_{\mathrm{ACT}} / \mathrm{E}_{\mathrm{RXN}}\right)$ are in $\mathrm{kJ} / \mathrm{mol}$. 
(A)
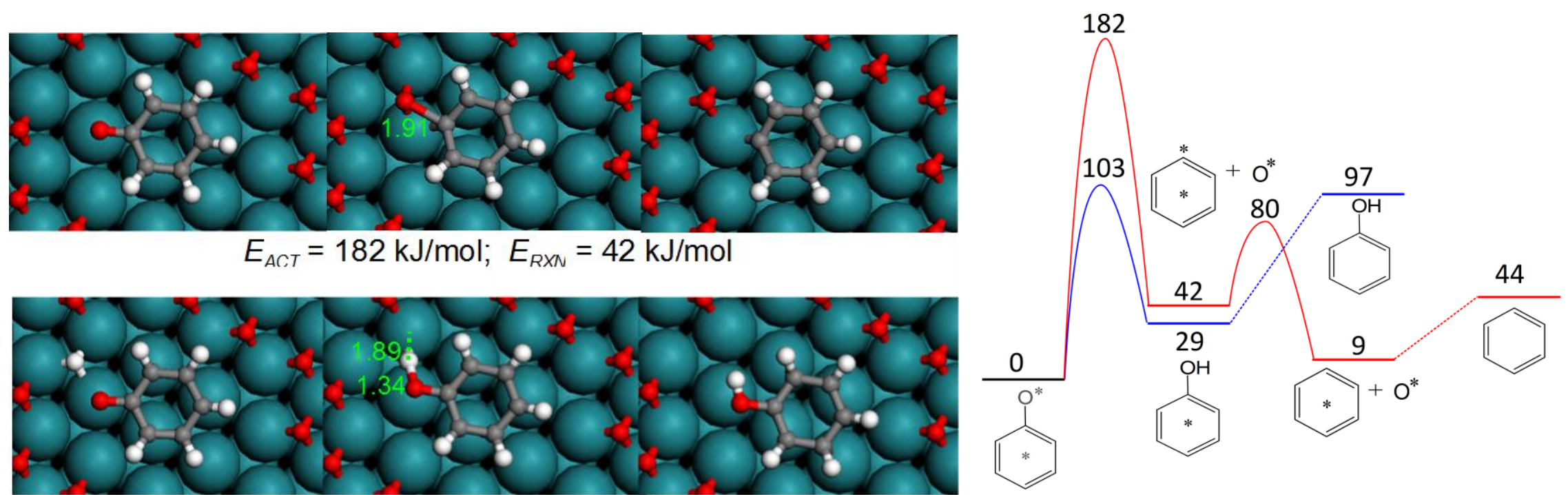

$E_{A C T}=103 \mathrm{~kJ} / \mathrm{mol} ; E_{R X N}=29 \mathrm{~kJ} / \mathrm{mol}$

Fig. 10. DFT calculated deoxygenation (A) and hydrogenation (B) of the phenoxy intermediate on 7/16 ML O*-covered $\mathrm{Ru}(0001)$ and their corresponding energy diagrams. 


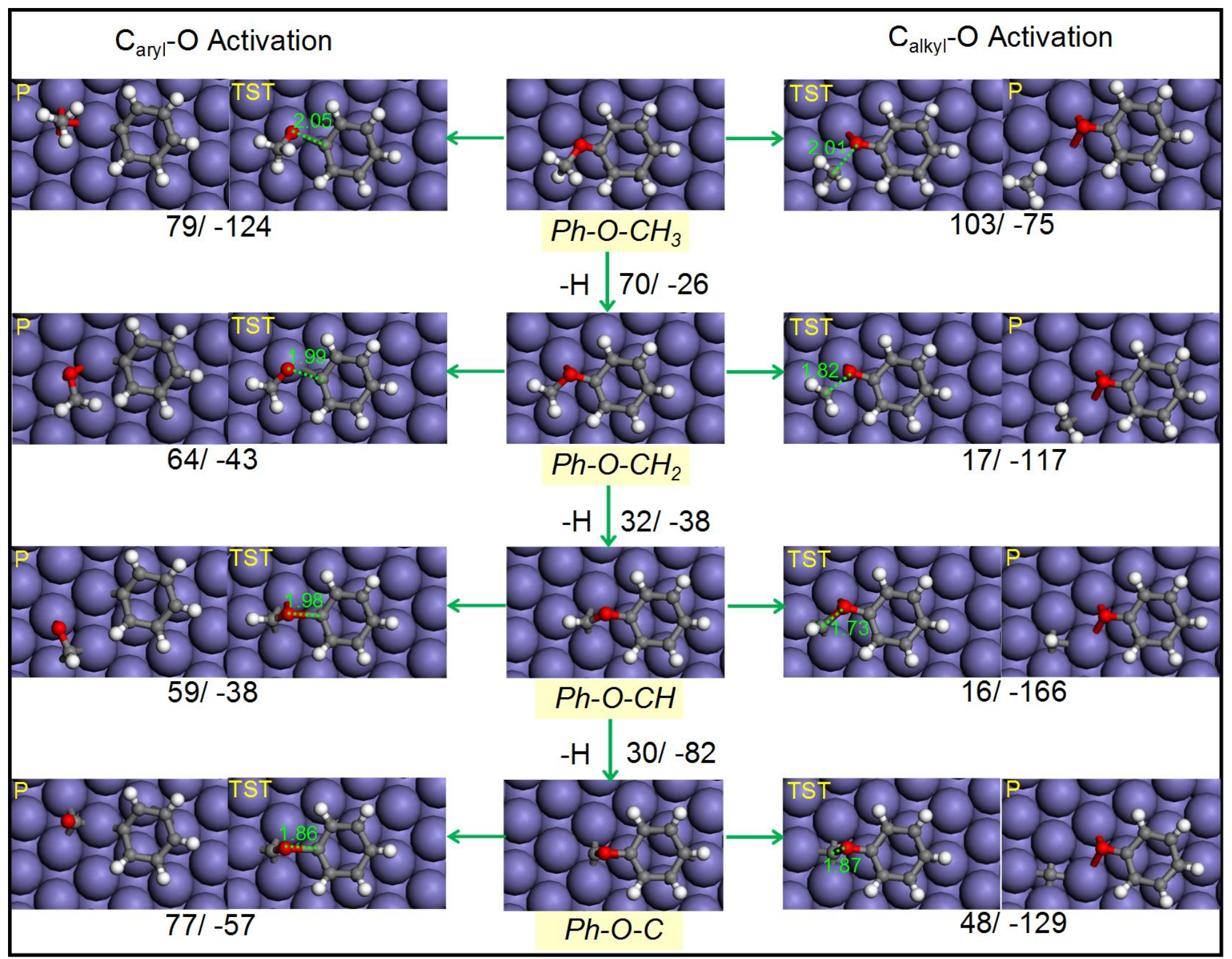

Fig. 11. DFT calculated reactant, transition state and product structures for the $\mathrm{C}_{\text {aryl }}{ }^{-} \mathrm{O}$ bond breaking, $\mathrm{C}_{\mathrm{alkyl}}-\mathrm{O}$ bond breaking and dehydrogenation reactions of different $\mathrm{Ph}-\mathrm{O}-\mathrm{CH}_{\mathrm{x}}(\mathrm{x}=1 \sim 3)$ intermediates over $\mathrm{Fe}(110)$. The energetics $\left(\mathrm{E}_{\mathrm{ACT}} / \mathrm{E}_{\mathrm{RXN}}\right)$ are in $\mathrm{kJ} / \mathrm{mol}$. 
(A)

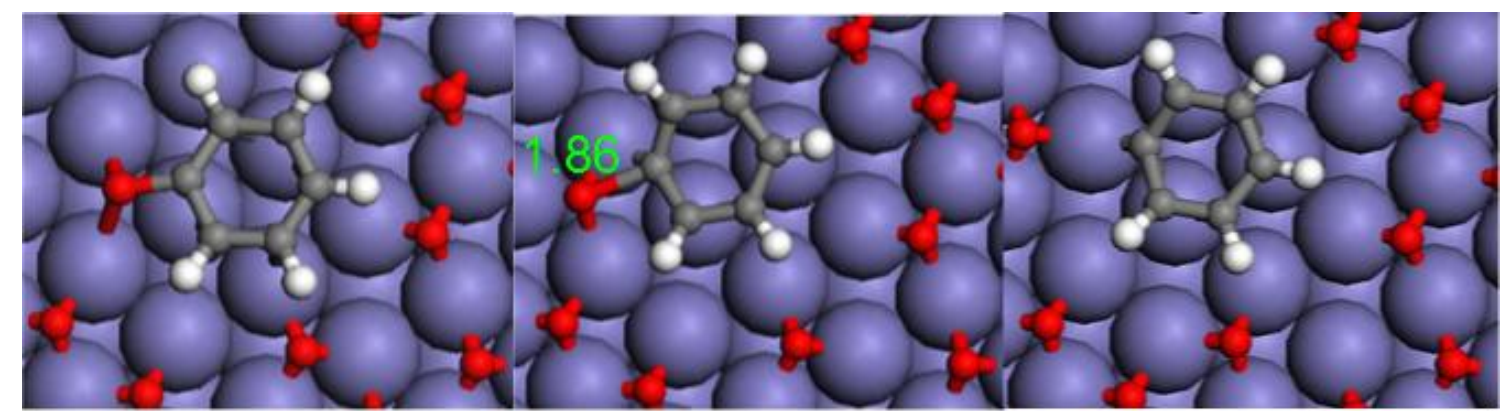

$$
E_{A C T}=110 \mathrm{~kJ} / \mathrm{mol} ; E_{R X N}=-13 \mathrm{~kJ} / \mathrm{mol}
$$

(B)

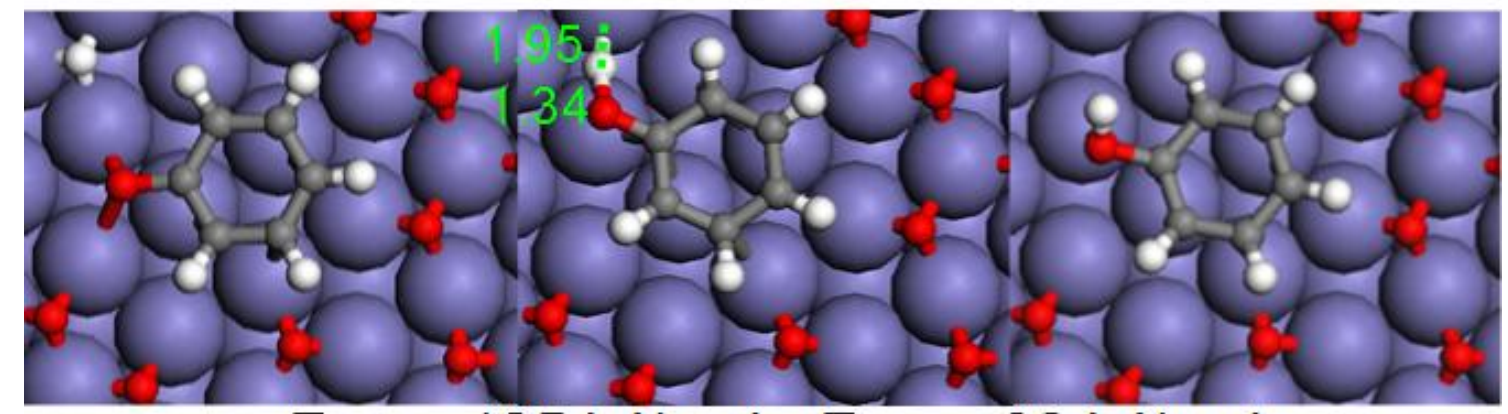

$$
E_{A C T}=125 \mathrm{~kJ} / \mathrm{mol} ; E_{R X N}=86 \mathrm{~kJ} / \mathrm{mol}
$$

Fig. 12. DFT calculated deoxygenation (A) and hydrogenation (B) of the phenoxy intermediate on 7/16 ML O*-covered Fe(110). 


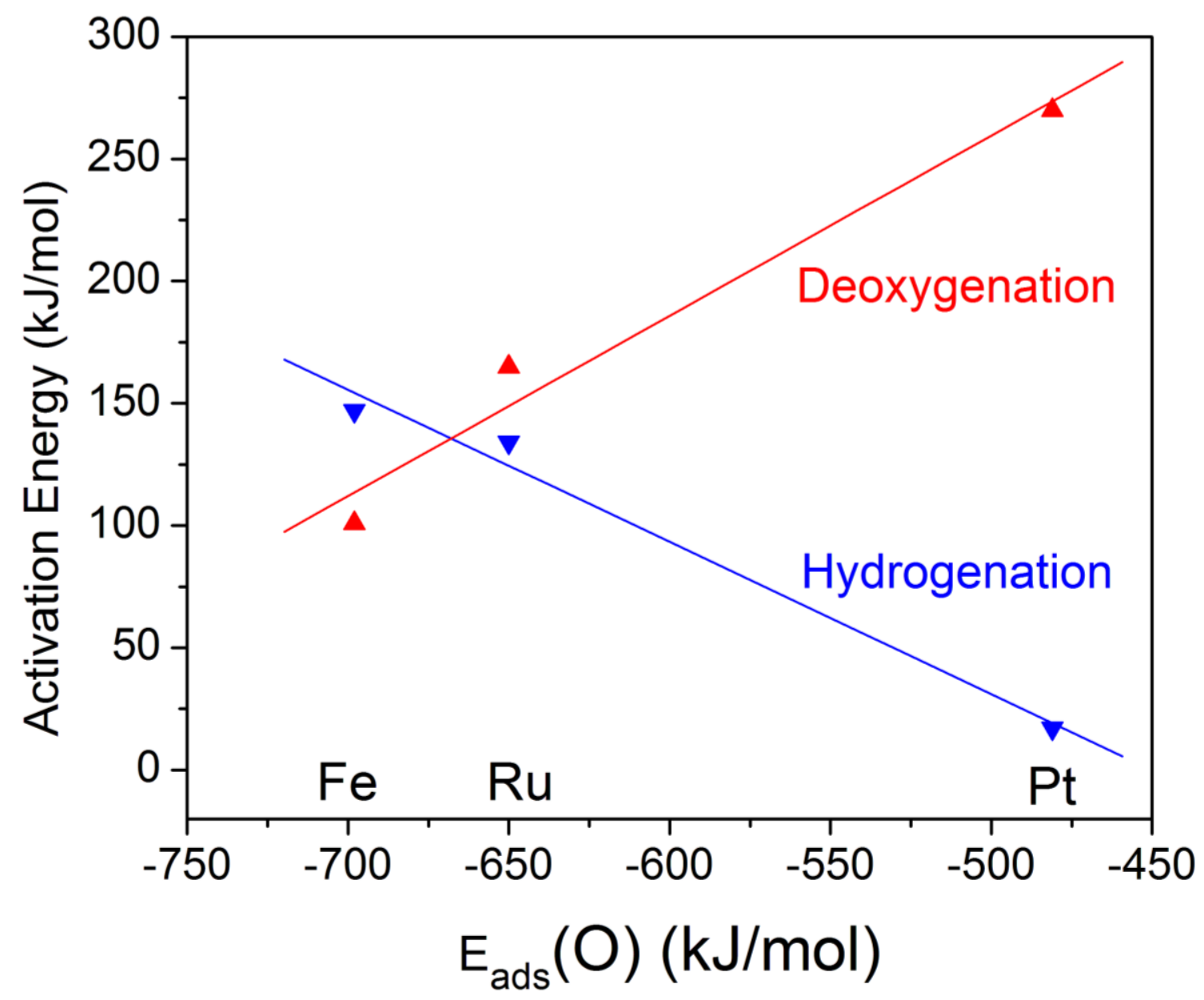

Fig. 13. Correlation between the intrinsic energy barrier for the hydrogenation reaction and deoxygenation reaction of phenoxy on different metal surfaces and the adsorption energies of the atomic oxygen (oxophilicity) on these metal surfaces. 


\section{${ }^{\star}$ Graphical Abstract (for review)}

Hydrogenation

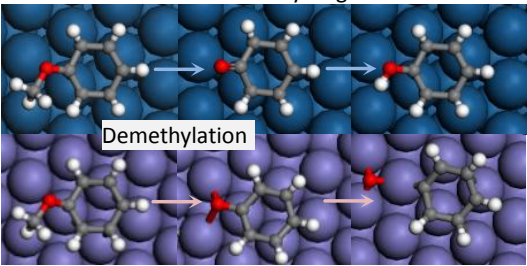

Deoxygenation
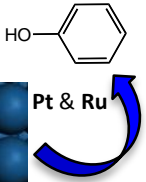

$\mathrm{Ru} \& \mathrm{Fe}$
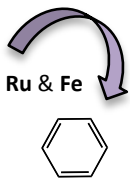